\title{
NEUROPSYCHOPHARMACOLOGY REVIEWS Sex differences in antidepressant efficacy
}

\author{
Tara A. LeGates ${ }^{1}$, Mark D. Kvarta ${ }^{2}$ and Scott M. Thompson ${ }^{1,2}$ \\ Sex differences have been observed across many psychiatric diseases, especially mood disorders. For major depression, the most \\ prevalent psychiatric disorder, females show a roughly two-fold greater risk as compared to males. Depression is sexually dimorphic \\ with males and females exhibiting differences in clinical presentation, course, and response to antidepressant treatment. In this \\ review, we first discuss sex differences observed in depressed patients, as well as animal models that reveal potential underlying \\ mechanisms. We then discuss antidepressant treatments including their proposed mechanism of action and sex differences \\ observed in treatment response. We include possible mechanisms underlying these sex differences with particular focus on \\ synaptic transmission.
}

Neuropsychopharmacology (2019) 44:140-154; https://doi.org/10.1038/s41386-018-0156-z

\section{INTRODUCTION: SEX DIFFERENCES IN DEPRESSION}

Depression is the most prevalent mood disorder and a leading cause of mortality and morbidity worldwide. Despite its high incidence and socioeconomic impact, the etiology of depression remains poorly understood. It involves a combination of genetics and environmental factors as well as the dynamic interaction of a number of brain regions, however, it is not clear how these factors interact to trigger depression. Adding to this complexity are the differences observed between men and women. Women are nearly twice as likely as men to suffer from depression [1], and more than $2 / 3$ of suicide attempts are by women [2]. Female depressed patients show greater severity, earlier age of onset, and increased duration of depressive episodes as compared to male patients [3]. The clinical presentation of symptoms of depression is sexually dimorphic as well, including differences in comorbid conditions [3]. Currently, the antidepressants commonly used for the treatment of depression are selective serotonin reuptake inhibitors (SSRIs) and tricyclics (TCA). Yet, these are successful in only a fraction of the population and take weeks to months to be effective in responders. Efficacy also differs between the sexes. Evidence put forth in an attempt to explain the disparity in depression and antidepressant response between males and females includes differences in neuronal circuitry, hormone levels, and metabolism [4-6]; however, the reason for these sex differences remains unclear.

Despite the evidence for greater prevalence of depression among women, there is considerably less attention devoted to studying depression in females or sex differences in depression. In fact, many of the animal models used to study biological mechanisms of depressive symptoms or of antidepressant response rely solely on male subjects ignoring a critically important study population. The development and verification of these assays in males has without a doubt been useful in reducing variability and producing meaningful data with respect to depression and antidepressant response in males. As sex differences result in variation in each step between animal behavior and clinical presentation of depression, the optimization of animal models for application in males only has made it exceedingly difficult to incorporate females into this same framework. This disconnect makes the already challenging study of the pathophysiology underlying depression even more difficult, obscuring and delaying the development of broadly effective antidepressants. This review aims to highlight the important neurobiological factors underlying sex differences in depression and antidepressant response. In delving into mechanisms that potentially explain these differences, we will dedicate our focus to neuronal circuits and synaptic transmission, as other important aspects, such as hormone regulation and pharmacokinetics have been reviewed extensively elsewhere [4, 7-11]. Investigation into the pathophysiology underlying depression has aided in our understanding of antidepressant response and efficacy. Similarly, knowledge regarding sex differences in depression is crucial to understanding differential antidepressant efficacy. Therefore, we will begin this review by discussing sex differences in depression in both humans and animal models.

\section{Humans}

Women have roughly twice the lifetime rates of depression as men $[12,13]$. According to the latest NHANES survey data for 2013-2016 amongst adults 20 and over, women were roughly twice as likely to be suffering from depression as men in a given 2week period ( $10.4 \%$ for women, $5.5 \%$ for men), with an overall rate of $8.1 \%$ [1]. However, this disparity is not an absolute throughout the lifespan. Depressive disorders through childhood have a relatively low prevalence estimated at $<5 \%$ overall, and are reported at similar rates by sex, or at even greater rates in males than females (e.g. [14]). Beginning with puberty and on into young adulthood, incidence of depressive disorders rise sharply, with a greater increase in females compared to males. The greatest predictor of the disparity is pubertal development, specifically Tanner Stage III [15]. By age 13-15, females begin to suffer from dramatically higher rates of depression than males [16]. In a 10-

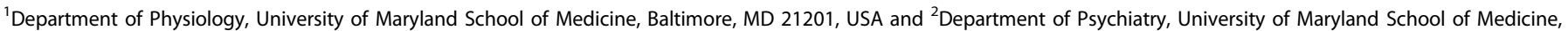
Baltimore, MD 21201, USA

Correspondence: Tara A. LeGates (tlegates@gmail.com)

Received: 11 March 2018 Revised: 6 June 2018 Accepted: 10 July 2018

Published online: 20 July 2018 
year longitudinal study of 1037 children in New Zealand followed from ages 11 to 21, the lifetime prevalence of at least one major depressive episode meeting full diagnostic criteria increased from $1.8 \%$ to $20.7 \%$ in males and from $0.3 \%$ to $42.6 \%$ in females [17].

Patients who are depressed do not comprise a homogenous population of symptomatology. According to the latest Diagnostic and Statistical Manual of Mental Disorders (DSM-5), a diagnosis of major depressive disorder (MDD) requires at least 5 out of 9 possible symptoms present during the same 2-week period, and must include either (1) anhedonia or (2) depressed mood, or both. Other criterion symptoms include (3) insomnia or hypersomnia, (4) changes in appetite or weight, (5) changes in psychomotor status, (6) fatigue or loss of energy, (7) worthlessness or guilt, (8) diminished concentration or indecisiveness, or (9) suicidal thoughts or behaviors. Using these criteria, it is plain to see that there are a myriad of ways-227 in total-to qualify for a diagnosis of depression by checking combinations of anywhere from 5 to 9 symptoms. Furthermore, several of the criteria can be met in opposite ways, greatly increasing the range of clinical presentations to 14,528 possible combinations of criteria. It is thus possible for two patients diagnosed with MDD to share no common symptoms [18]. Zimmerman and colleagues examined 1566 patients who met MDD criteria, and observed 170 of these 227 possible combinations. The top 9 combinations only composed about $40 \%$ of the study population. This highlights potential problems that conflating diagnostic heterogeneity, either in a human study or an animal one, can yield for attempts to unravel pathophysiological and etiological mechanisms, as well as the search for biomarkers or broadly effective treatments for the entire depressed population.

Given this heterogeneity in presentation across the total population of patients that present with MDD, it is not surprising that the manner in which women suffer from depression tends to differ from men, in addition to the greater overall rate at which women suffer. One of the largest and longest concerted efforts to evaluate depression treatment to date provided important data on disease presentation. The Sequenced Treatment Alternatives to Relieve Depression (STAR*D trial) enrolled over 4000 outpatients seeking depression treatment at 41 primary and specialty care sites to compare first-line and subsequent switches and add-on therapies towards an endpoint of remission [19]. At baseline, women enrolled in the study reported greater depression severity, greater rates of hyperphagia and weight gain, hypersomnia, interpersonal sensitivity, and other somatic symptoms like gastrointestinal disturbances as well as co-morbid somatoform disorder. Women were also more likely to report anxiety-related disorders, bulimia, and prior suicide attempts, but less current suicidal ideation [20]. Men, on the other hand, were more likely to report comorbid substance abuse. Both sexes were equally likely to report irritability. Although women make two-time to threetime more suicide attempts than men [2], they are less likely to be lethal. The greatest disparity in suicide attempt rates is driven by adolescent age females [21, 22].

Rumination, chronic negative circumstances or strain, and a low sense of mastery have each been found to be more common in women [23]. These individual components contribute to greater depressive symptoms in women, and depressive symptoms feed into greater rumination and less mastery over time, setting the stage for positive feedback and recurrence in women in particular [24]. Men have been found to be more likely to forget past episodes of depression [25], likely reflecting a lower likelihood of a ruminative coping strategy compared to women. Subclinical depression symptoms are also more common in women than in men [26]. Finally, heritability of MDD in women is greater than in men, suggesting a higher genetic vulnerability [27].

It is important to note that differences in disease presentation are not absolute, which might suggest an altogether separate etiology, but that these trends demonstrate key signs and symptoms that are more prevalent in women than in men. Understanding these differences as well as commonalities may shed light into the fundamental mechanisms which translate into altered mood and behavior in both sexes, as well as inform tailored diagnostic and treatment intervention strategies.

Many of these observations on variation in clinical presentation have recurred in the literature [28], resulting in efforts to categorize subtypes. For example, Silverstein described "somatic depression" associated with greater fatigue and disturbances in appetite and sleep, with resulting disparity in the rate of this somatic depression (females $15.2 \%$ lifetime vs. males $7.0 \%$ ), but not in rates of depression that did not involve all three of these somatic categories (female $6.9 \%$ vs. male 6.0\%) [29]. Atypical depression characterized by intact mood reactivity, as well as prevalence of hypersomnia and weight gain is associated with female gender, younger age of onset, greater severity and disability, and higher number of suicide attempts, but is no longer delineated in the DSM [30,31].

Risk factors for depression include a combination of genetic and environmental components, such as family history of depression and exposure to stress, with interactions between traits and experience increasing likelihood of onset of a depressive episode. A study in randomly selected American adolescents suggested that greater early adolescent challenges contributed to differences in affect in high-school aged teenagers [32], findings which highlight a role for the so-called stress-diathesis model of depressive behavior in which exposure to stress interacts with with existing psychobiological traits. Classically in this context, stressful life events interact with a negative inferential cognitive style to generate hopelessness and predispose towards depression [33]. In a prospective study of adolescents, negative inferential styles at baseline interacted with negative events over a 5-month follow-up period to predict depression and anhedonia specifically in females [34]. The stress-diathesis model has been developed further beyond the interaction of stress and cognitive style to stress interactions with the biological framework in a genetic epigenetic context $[35,36]$. A growing body of evidence supports roles of both prenatal and early life stress imparting vulnerability for mood-related symptoms in adulthood, however, caution should be taken when interpreting human data based on self-report and recollection.

No discussion on sex differences is complete without mention of the effects of the reproductive cycle on depressive disorders. As mentioned above, the sex-based disparity in depression prevalence emerges with puberty. For many women, severity of symptoms of existing depression increases in the premenstrual phase [37]. In data from the STAR*D trial, $66 \%$ of women reported premenstrual exacerbations in their symptoms [38]. Of note, this was associated with longer depressive episodes and shorter latency to relapse. The increased incidence of new onset depressive symptoms in women appears to be reduced dramatically with menopause [39]. Women with established history of depression retained an eight-fold greater risk of depressive symptoms after menopause and a 4-6-fold increased risk in relapse [39]. Regarding the effect of pregnancy and birth, DSM-5 includes a peripartum-onset specifier for a depressive episode in the third trimester to up to 4 weeks after childbirth [40]. In one study of women with postpartum depression identified by Edinburgh Postnatal Depression Scale, $40 \%$ began post-partum, $\sim 33 \%$ began during pregnancy, and $\sim 26 \%$ had depressive symptoms before becoming pregnant [41]. A number of studies have also examined the interaction between depression and menstrual disturbances further linking sex hormones and depression $[42,43]$.

A myriad of specific effects of sex hormones will be discussed in further detail below. Furthermore there are a wide range of developmental effects to consider regarding biologically determined sex differences. These include effects of $X$ and $Y$ 
chromosomal genes, organizational effects of gonadal steroid exposure during development, activational effects of reproductive hormone exposure throughout the lifespan, as well as the effects of parental stress prior to conception that have differential effects in males and females on depression-related behaviors and stress regulation (for an excellent review, see [11]). No single manuscript is likely to be exhaustive in this regard, although we touch briefly on those most pertinent to our examination of current efforts to understand sex differences in the key neurobiological circuitry underlying the patho-etiology of depression and antidepressant treatment.

\section{Animal models}

Depression is a multifaceted, heterogeneous disease with limited knowledge regarding predisposing factors. Animal research is an essential method for improving our understanding of these factors and underlying neuronal substrates. Depression cannot be fully recapitulated in an animal model-recurrent thoughts of death or suicide or excessive thoughts of guilt are clearly not measurable in animals. Instead, focusing on and modeling one core sign or symptom of this disorder has the benefit of simplifying a complex disorder like depression into behaviors that are easier to measure and are likely to involve fewer genes [44, 45].

The ideal animal model would have identical symptoms (face validity), causal factors (construct validity), and response to treatments (predictive validity) to the human disease it is attempting to replicate. Strategies that have been used to model depression range from environmental to genetic manipulation. We will cover many, but by no means all, of these models and discuss sex differences observed as well as their roles in depression.

\section{Stress-based models}

Depressed patients report more negative or stressful life events than non-depressed individuals, with exposure to stress one of the most prominent environmental factors associated with onset of a depressive episode [35]. Women, to a greater degree, report interpersonal stressors as a contributing factor. This is particularly greater in adolescents and young adults, when the disparity in depression is greatest. The impact of stressors is dependent upon characteristics of the stressor itself (e.g. severity, chronicity, predictability), as well as an individual's history and ability to cope with stress $[46,47]$. This sensitivity to stress is greater in females, who show an increase in the magnitude of the stress response and longer recovery time as compared to males. There are clear sex differences in hypothalamic-pituitary-adrenal (HPA) axis regulation in rodents, and the connection between dysregulation of stress response and development of depression has been reviewed elsewhere $[6,48]$. In this section, we will discuss some of the more widely used paradigms including observed sex differences.

Chronic stress. While stressors encountered on a daily basis are often acute in nature, it is often the case that individuals endure chronic stressors. These can be related to psychosocial issues, financial impositions, health, discrimination/stigma, or a combination of different factors. The stressors can be inconsistent, unpredictable, ambiguous, and uncontrollable. They may differ in severity or quality over time, making it difficult to establish adequate coping methods, or limiting the ability to take preparatory steps. Chronic stress paradigms used in animal models have sought to recapitulate this by exposing animals to stressors over the course of many days. For example, chronic unpredictable stress (CUS) (also referred to as chronic mild stress) exposes animals to different stressors daily over the course of 2-3 weeks [49]. While the exact stressor selection and order of rotation varies by investigator, some examples include forced swim, wet bedding, restraint, strobe light, white noise exposure, and cage tilt. Changing the stressor daily prevents animals from anticipating or adapting to stress exposure. As a result, male animals show anhedonic-like behaviors as measured by the sucrose preference test (SPT) and social interaction test (SIT). However, the use of sucrose preference to model anhedonia has been difficult to recapitulate in females [50, 51]. Additionally, sucrose palatability can be modulated by the estrous cycle [52].

Learned helplessness. One of the most widely used models of depression has traditionally been that of 'learned helplessness,' inspired by early observations in dogs thought to represent despair or hopelessness [53]. Animals are exposed to either escapable shock, yoked inescapable shock (in which shock exposure is dictated by the actions of a fellow "yoked" rodent), or no shock exposure. They are subsequently tested in a behavioral task, most often one that assesses escape performance. In this paradigm, the inescapably shocked animals subsequently show frequent failures to escape from shock, whereas rats or mice that had previously been exposed to either escapable shock or no shock do not exhibit such deficits [54]. Studies examining sexdependent effects of this test found that while male animals exposed to inescapable shock showed deficits in escape behaviors, female behavior remained unchanged [55]. Additionally, inescapable shock alters exploratory and anxiety-like behaviors, which appeared to be longer lasting in males than females [56].

Social stress. The main source of stress in humans is social in nature and is thought to contribute to the development and expression of mood disorders [57]. Animal models that involve a social context may be more appropriate as they represent situations that may be presented to humans for which the response is evolutionarily conserved. This is salient in the context of sex differences as interpersonal stress, in particular, drives the increased exposure of females to stress and has been shown to partially mediate the increased prevalence of depression in females after puberty, while women in general are more likely to express affiliative behavior and seek support when faced with stress as a coping style $[58,59]$. In animals, the most widely used social stressors are defeat, isolation, and crowding. These types of stressors are often integrated into CUS described above.

Social defeat. The chronic social defeat stress (CSDS or SDS) paradigm is based on the establishment of a territory by a male rodent and its defense against unfamiliar male intruders [60, 61]. In this paradigm, a male rodent (the intruder) is placed into the home cage of another male (the resident). The intruder is physically confronted and defeated by the resident. The resident is usually of a more aggressive and larger strain than the intruder. In rats, the resident is usually paired with a female while the intruder is individually housed. Conversely, with mice, the resident is kept isolated whereas the intruder is group-housed. The resident has also had previous experience of victory in such encounters. There are many variations of this model that involve different durations of exposure or include additional threats of attack. The greatest limitation of this model is that it is almost exclusively used in males as it is difficult to obtain strong dominance relationships or aggressive encounters in females. However, a recent study employed designer receptors exclusively activated by designer drugs (DREADDs) to promote male aggression toward females [62]. Using these males, Takahashi and colleagues were able to induce social defeat in females and begin to examine some of the underlying neurobiological changes [62]. Another female model exploits maternal aggression, in which a non-pregnant female is attacked by a lactating female [63].

Defeated animals show a variety of behavior changes following defeat. Regarding social behavior, defeated males show a decrease in social interaction with novel conspecific males 
$[64,65]$. They also show a decrease in mating and aggressive behaviors [66]. These observations are thought to reflect social withdrawal, discussed above. Social defeat also alters many nonsocial behaviors including decreased locomotor activity, reduction in food and water intake, anxiety-related behaviors, and drug seeking behavior, as well as reduced brain-reward behaviors seen during ICSS [67-71]. Increased immobility in the FST has also been observed, while there have been mixed results detailing effects on sucrose preference [71-74].

Housing conditions. Isolation has been associated with numerous physical and mental health problems, and several studies have indicated that loneliness may play a role in the development and persistence of depression [75-77]. This can be studied in animal models by single housing animals for a prolonged period of time (on the order of weeks). Prolonged isolation leads to increased immobility in the FST, changes in reward-related behaviors as measured by decreased sucrose preference, changes in sexual behavior, and drug-associated behaviors, as well as increased anxiety-like behaviors [78-81]. Studies using male and female animals have found that both sexes show increased anxietyrelated behavior and decreased sucrose preference in response to social isolation, though the effects appear to be more prominent in males $[82,83]$.

To introduce unpredictability to the housing condition, researchers have utilized a chronic social instability paradigm where isolation and crowding conditions are alternated [84-86]. Additionally, animals are rotated among social groups during those crowding phases. This has been found to lead to neuroendocrine changes, anhedonia, and increased anxiety-like behavior [84-86]. Many of these traits are inherited by offspring of these animals implicating the involvement in stress-induced epigenetic changes [87]. The advantage of this paradigm is that it has been found to be effective in both males and females, and is often incorporated into CUS approaches [84, 88].

Maternal deprivation. A specific form of social isolation is focused on isolation in young animals as evidence indicates that early life traumatic experiences are associated with psychopathology including depression later in life [89]. Maternal deprivation (MD) models early life stress through daily separation of new born pups from their mothers during the first few weeks of life. Behavior and neurobiological changes are then assessed in adolescent or adult animals. This early life isolation results in persistent neurobiological changes, and depression and anxiety-related behaviors can be observed in adulthood [90-94]. Moreover, this depression-like behavior can be transmitted across several generations reflecting epigenetic vulnerability to stress [95].

Adolescent mice exposed to maternal separation show sexdependent alterations in behavior in response to the learned helplessness paradigm, with males demonstrating loss of controllability in an escapable shock condition. In contrast, females demonstrated motivational impairment in a no-shock condition. This effect, however, was absent in adulthood as females no longer displayed helpless behavior [96].

Although maternal deprivation induces the same endocrine changes in males and females, such as increased corticosterone levels, sexual dimorphisms have been observed in the neuronal and behavioral changes induced by maternal deprivation [97]. Several studies in adult rats have shown that separated male rats exhibit a higher immobility as measured by FST [98-101], as well as anhedonia [101, 102]. Studies using adult females have found that maternal separation has no effect on depression-related behaviors as measured by FST or SPT $[102,103]$.

Surgical/genetic models

Olfactory bulbectomy. Surgical removal of the olfactory bulbs $(\mathrm{OBX})$ in rodents leads to a number of behavioral, cognitive, and neurochemical changes, which are normalized with antidepressant treatment [104]. While there appear to be some differences between the rat and mouse models, OBX has been a useful model in the study of antidepressant efficacy [104]. OBX increases the immobility time in the FST and TST in both rats and mice [106-108], and causes hyper activity and anhedonia as measured by the SPT in mice [109-112].

There have been very few studies involving female subjects in the OBX model and even fewer dedicated to comparing sex differences. However, male and female OBX animals that have also been gonadectomized/ovariectomized exhibit higher activity levels than intact OBX and control animals. The effect of gonadectomy was more robust in males. Female OBX rats exhibited lower sucrose preference levels than male OBX rats. This difference was true for both intact and gonadectomized/ovariectomized rats [113]. These results suggest that hormones may have activational effects on activity changes induced by OBX and organizational effects in the marked anhedonia exhibited by female OBX mice.

Genetic selection/selective breeding. There is a genetic component associated with depression and a number of studies have sought to determine these genetic determinants, with dozens of genetically modified mouse strains associated with depressed phenotypes [114]. Many studies have used transgenic or knockout/knock-in mice as a targeted approach to study specific genes that might underlie genetic predisposition to depression. An alternative approach to studying the genetic component of depression is through selectively breeding for a specific phenotype. There are many examples of this approach, but one example is the Flinders sensitive line rats. These rats have been created by selectively breeding Sprague-Dawley rats for their hypersensitivity to cholinergic agonists; a characteristic that has been observed in depressed humans, as well [115]. These rats display depression-like behavior as shown by increased immobility in the FST, and reversal of depressive-like behavior has been observed in response to treatment with a variety of antidepressants [115]. Females do not exhibit enhanced immobility, but instead show decreased latency to become immobile, in comparison to Sprague-Dawley controls [116].

Additional models/considerations. Common cognitive deficits in depression include impairment of concentration and selective attention towards or processing of negative stimuli. It is believed that this negative bias serves to increase salience of depressive elements, thus prolonging and exacerbating depressive episodes [117], and may partly explain or interact with rumination, which has been shown to be more prevalent in women [118]. Despite the prevalence of cognitive dysfunction in depression, many studies do not incorporate any cognitive function assessment into their animal models $[119,120]$. Even fewer studies have examined potential sex differences, although it does appear that females may exhibit more negative bias at baseline [121, 122] complementing evidence for increased negative recall bias in women [123].

In addition to cognitive dysfunction, there are many homeostatic changes associated with depression, such as altered sleep and circadian rhythms, as well as changes in feeding and metabolism. These somatic symptoms are less frequently incorporated into animals models, and more frequently observed in depressed women [20]. Incorporating these deficits into animal models would be a clear and necessary step to expand upon current models in order to gain better insight in the pathophysiology underlying depression and antidepressant response. In parallel, better characterization and understanding of sex differences in expression of depression symptomatology are key to developing more valid models in which to further dissect underlying mechanisms and develop the next generation of antidepressant treatments. 


\section{ANTIDEPRESSANT TREATMENT}

Tricyclic antidepressants (TCAs)

The TCAs are derived from antihistaminic compounds, and the first, imipramine was introduced in 1957 [124]. They block reuptake of serotonin and norepinephrine, which is thought to contribute to their therapeutic action (Fig. 1). The degree of selectivity of inhibition of serotonin versus norepinephrine transporters differs among the family of TCAs with desipramine and maprotiline being most potent at the norepinephrine transporter and clomipramine being most potent at the serotonin transporter [125]. In addition to their actions at serotonin and norepinephrine transporters, TCAs also exhibit anticholinergic, antiadrenergic, and antihistaminergic activity owing to their reported side effects [125]. Additionally, at high levels, they can inhibit sodium channels or cause serotonin syndrome making them potentially lethal [126] and increasing the risk of suicide by overdose [127]. This is particularly relevant for female patients as reports have shown increased suicide attempts by antidepressant overdose [128].

The therapeutic use of TCAs for treating depression was not only a significant advancement in the treatment of this disorder, but it revealed the potential to understand the neurological basis of depression. Their use has fallen out of favor due to better safety profile of newer medications, however they are still employed in treatment-refractory cases. There is also evidence that they may be more effective in adult men and in older women than SSRIs $[129,130]$. From the successful treatment of depression with TCAs and studies on serotonergic dysfunction emerged the serotonin hypothesis of depression.

\section{SSRIS}

The serotonin hypothesis of depression has driven antidepressant development for the better part of six decades, ultimately leading to SSRIs and later serotonin/norepinephrine reuptake inhibitors (SNRIs) (Fig. 1). Inhibition of serotonin reuptake leads to increased activation of the 14 subtypes of serotonin receptor, each with a unique pattern of expression and activation. An estimated $15.9 \%$ of adult women in the US take antidepressants, compared to $7.7 \%$ of men [131], reflecting the higher rate of depression overall. Six of the top ten prescribed antidepressants in the US are serotoninbased antidepressants.

Alongside explosive drug development leading to dozens of prescribed serotonin-based antidepressants, extensive and thorough basic research continued into the role of monoamine depletion in depressive symptomatology and has not fully satisfied the predictions of the hypothesis, with inconsistent and inconclusive evidence leaving considerable debate as its validity to explain depression as a single disease [132]. Mirroring the incompleteness of the underlying serotonin hypothesis is an incompleteness in patient response to this class of secondgeneration antidepressant medications. The response rate to this first line in antidepressant treatment is around $50 \%$, with $70 \%$ of patient failing to fully remit after a 12-week course [133, 134]. These limitations have guided the most recent quest for the next generation of antidepressants, discussed in the next section. However, this too yields resolution in which to examine sex differences.

\section{Fast acting antidepressants}

Drugs targeting the monoamine system have been the standard of care over the past 50 years, however there are some significant limitations associated with this class of drugs. Only a fraction of patients experience relief of depression symptoms upon antidepressant administration, and among that fraction of responders $(\sim 30 \%)$, it can take weeks to months before patients feel those effects. Additionally, there are various side effects associated with these drugs that decrease compliance with drug regimens. However, there was not a significant shift in focus on novel antidepressants until the provocative finding that acute administration of ketamine could produce rapid (within hours) antidepressant effects [135]. This effect has been found to last for up to 2 weeks after a single administration [136, 137]. Furthermore, ketamine has also been found to be efficacious in treatment resistant patients, who failed to respond to monoamine-based antidepressants [136, 137]. This revolutionized the field of antidepressant research and pivoted the focus of the field to novel antidepressant mechanisms.

While the abuse potential for ketamine has restricted access to this treatment to medically staffed environments, these findings have aided much of the preclinical work on depression and antidepressant mechanisms. The mechanism of action for ketamine is a highly debated topic. Ketamine is an ionotropic glutamatergic N-methyl-D-aspartate receptor (NMDAR) antagonist and work has suggested that NMDAR blockade influences downstream intracellular signaling pathways (Fig. 1). In one model, this is shown to occur through inhibition of eukaryotic elongation factor 2 (eEF2) kinase ultimately leading to increased BDNF signaling, AMPAR insertion, and increased synaptic strength [138]. Another model suggests that NMDA receptor blockade increase mammalian target of rapamycin (mTOR) signaling, which increases synaptogenesis [139]. This was also shown to be the mechanism of action for another rapid acting antidepressant, scopolamine, a non-selective muscarinic receptor antagonist [140]. Recent work suggests that it may not be the action of ketamine on NMDAR that is important for its antidepressant effects, but rather the action of $(2 \mathrm{R}, 6 \mathrm{R})$-hydroxynorketamine (HNK), the major ketamine metabolite found in plasma and brain [141]. Administration of HNK was shown to elicit rapid antidepressant effects and synaptic potentiation, similar to ketamine, however HNK action does not appear to be through inhibition of NMDARs [141].

Despite the differences between these proposed mechanisms, they all seem to converge on the idea that ketamine exerts its antidepressant effects through an increase in activity in neural circuits associated with mood regulation. This has been key in the development of novel rapidly acting antidepressants that might have fewer side effects than ketamine. One approach to minimize potential side effects has been through targeting receptor subtypes with region-specific expression. a5-containing $\gamma$-aminobutyric acid type-A (GABA $A_{A} R$ ) are most strongly expressed in PFC and hippocampus [142]. The negative allosteric modulators of this subtype (L-655,708 and MRK-016) elicit rapid antidepressant action and increased excitatory synaptic strength, similar to ketamine [143]. However, in contrast to ketamine, these drugs do not have psychotomimetic or sedative side effects [144].

\section{Alternative neuromodulatory treatments}

Despite the array of pharmaceuticals available for depression, a significant proportion of depressed individuals is treatment-resistant as discussed above. Alternative strategies have been sought to alleviate depression symptoms in these patients. Despite differences in methodology, these techniques are all based upon the idea that depression results from altered neuronal circuits and stimulating those circuits can at least partially reverse this altered activity and produce antidepressant effects. We will only discuss a few such approaches here.

Electroconvulsive therapy (ECT) is an intervention whereby electricity is delivered to the brain to induce generalized seizures. It is effective in treating depression with a roughly $60 \%$ remission rate and is even effective in treatment resistant populations [145, 146]. However, concerns including cognitive side effects, in particular temporary memory impairment, have limited the penetration of ECT into broad clinical practice. The induction of seizure activity alters the function of neuronal circuits, which is thought to underlie the beneficial effects of ECT in the treatment of depression. More recent strategies have sought to emulate ECT with stimulation better targeted to brain regions known to be 


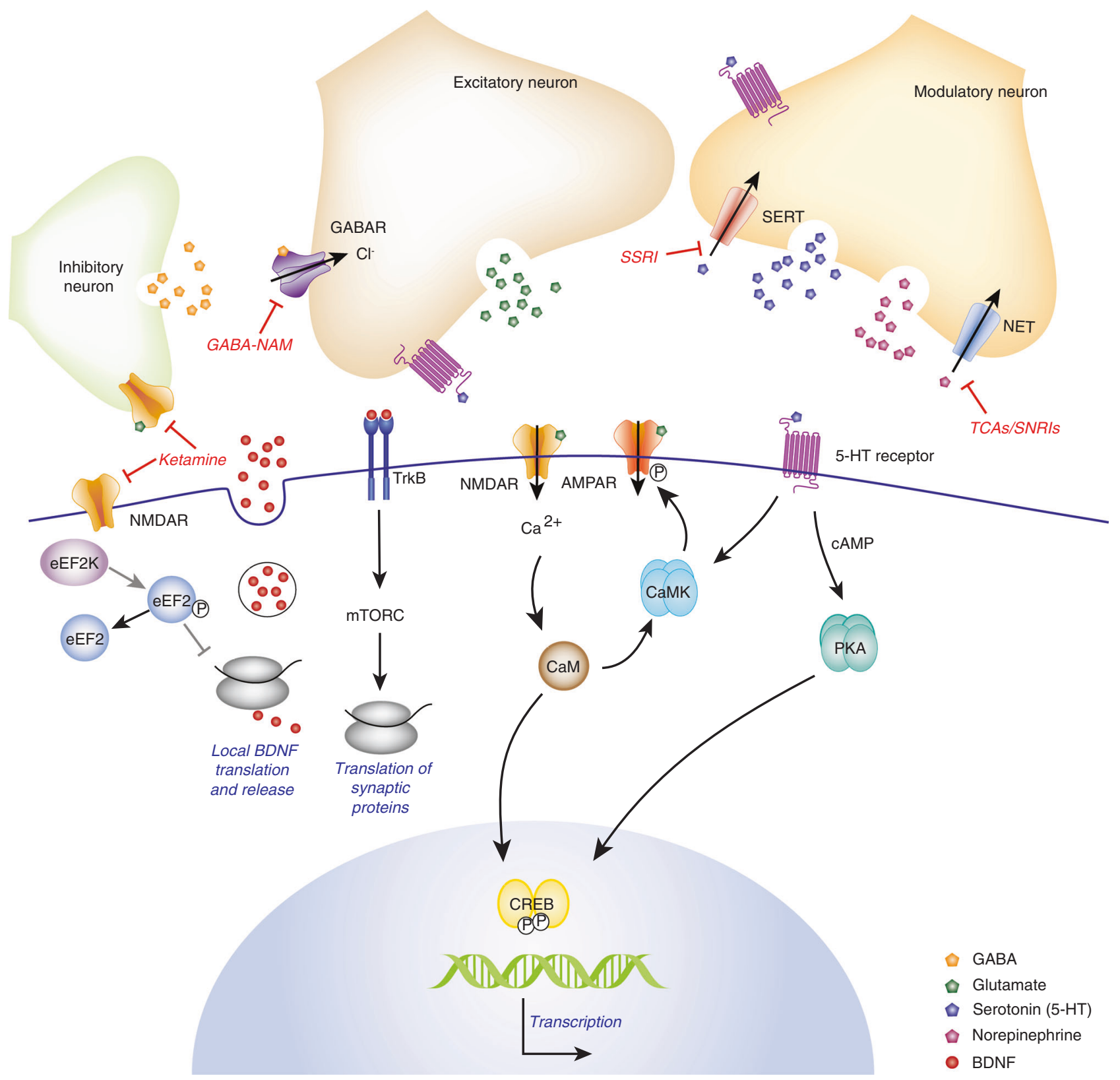

Fig. 1 Antidepressant mechanism of action. Schematic of the proposed mechanisms of action for antidepressants at the synapse level. Serotonin and norepinephrine are represented together for simplicity. Ketamine has two proposed mechanisms, which are both shown. One is block of extrasynaptic NMDA receptors, leading to repression of eEF2 kinase and dephosphorylation of eEF2, thereby disinhibiting translation of BDNF. The second mechanism is block of NMDA receptors on inhibitory neurons, leading to increased excitation, BDNF release, and activation of mTOR through a TrkB-dependent signaling cascade. GABA-NAMs are negative allosteric modulators of alpha5 subunitcontaining GABA receptors and thereby increase excitation and promote activity-dependent synaptic strengthening. SSRIs and TCAs act by blocking serotonin reuptake, increasing the synaptic concentration of serotonin, and thus increasing activation of serotonin receptors, thereby promoting activation of CaMK and PKA signaling and leading to increased synaptic strength via transcription and post translational modifications

involved in mood regulation, thereby reducing the negative side effects associated with altering whole brain activity.

Transcranial magnetic stimulation (TMS) uses alternating magnetic fields to induce electric currents in cortical neurons [147]. Multiple studies examining TMS targeting the prefrontal cortex have revealed positive antidepressant effects [148, 149]. Deep brain stimulation (DBS) involves implanting electrodes to stimulate specific brain regions [150]. These regions include subcallosal cingulate, ventral anterior internal capsule, and ventral striatum, which are all involved in regulation of mood and antidepressant response [150, 151]. Existing evidence is limited, a few studies using these neuromodulatory approaches have found equivalent efficacy in both males and females $[152,153]$. However, response to TMS may be modulated by hormone levels as response in premenopausal women was correlated with estradiol/ progesterone ratio while postmenopausal women were the least responsive to treatment [154].

\section{SEX DIFFERENCES IN RESPONSE TO ANTIDEPRESSANTS}

There is not a clear consensus on whether there are sex differences in pharmacotherapy antidepressant efficacy, likely 
due to variability in methodology, as well as a dearth of specific investigation in this regard. A number of studies have shown that men experience a better therapeutic response to TCAs than women $[130,155,156]$, whereas there is evidence that women respond better to SSRI treatment than men [129, 130, 157, 158]. This effectiveness was further exemplified in a study of patients given free choice of clinical interventions followed for up to 12 weeks: women were about $1.5 \times$ as likely to achieve remission as men, with most patients in the study taking either SSRIs or SNRIs [159]. In conjunction with findings that older women do not enjoy this superiority and that hormone replacement therapy has been found to eliminate a poor SSRI response [160], this suggests a role of female sex hormones in therapeutic response to SSRIs in particular. Estrogen has subsequently been shown to influence serotonin synthesis, as well as serotonin receptor binding and activity [161].

An alternative explanation is that the subtype of depression determines the antidepressant response. As discussed above, the presentation of symptoms differs between men and women, and women tend to show more somatic symptoms associated with atypical depression, which has been found to respond preferentially to SSRIs [162].

Because of the high incidence of poor or delayed response to antidepressant therapy, there has been extensive investigation into potential augmentation of traditional antidepressant pharmacotherapy. These include other medications with other indications such as lithium, triiodothyronine, and antipsychotics, as well as non-pharmacological interventions like bright light therapy. Such augmentation by estradiol treatment on SSRI effectiveness was mentioned above, but sex differences exist for other augmentation strategies as well. For instance, triiodothyronine (T3) has been found to accelerate response to TCA, and this effect is more pronounced in female patients [163]. Another study found that supplementing folic acid enhanced the effect of fluoxetine in women likely due to differences in resulting plasma folate concentrations [164]. Additional work into current and novel augmentation strategies may be useful in identifying approaches to optimize treatment in both males and females.

Currently, fast acting antidepressants are not widely used in humans; however, a few studies in rodents have suggested that females may be more sensitive to ketamine. Stress naïve females show an antidepressant response to a lower dose of ketamine as compared to males as measured by behavior in the FST $[165,166]$. In mice exposed to chronic stress, the long lasting antidepressant effects of ketamine (7 days post injection) are more apparent in males [166]. This increased sensitivity is absent in ovariectomized females and is only restored in animals receiving estrogen and progesterone [165], suggesting both hormones are required for the increased sensitivity observed in females. This was also found to increase hedonic responses to low-dose ketamine as measured by increased sucrose preference [167]. In contrast, gonadectomy and testosterone had no effect on male responses, however, progesterone administration rendered males sensitive to low-dose ketamine [167]. This implicates an activational role for estrogen and progesterone in mediating sensitivity to ketamine.

It should be noted that many studies using the forced swim test (FST) for screening antidepressants or assessing depression-like phenotypes have relied on male subjects and assumed that the behavioral response would be the same in females. However, conflicting results have emerged from studies that have considered sex differences (see [168]). Hormone levels do not appear to play a major role in influencing behavior in normally cycling rodents, although some studies have found differences across the estrous cycle. In ovariectomized rats, hormone levels play a role in modulating FST behavior, with estrogen withdrawal leading to increased immobility [169], and estrogen administration leading to antidepressant-like effects [170].

\section{POSSIBLE MECHANISMS UNDERLYING SEX DIFFERENCES}

If we consider depression as a result of altered neuronal circuitry, then differences in antidepressant response can emanate from sex differences in neuronal circuitry. Therefore, it is important to discuss sex differences in the neurobiology underlying depression as well antidepressant response. Here, we will focus on sex differences in synaptic transmission and include how hormones may contribute to these differences as the organizational and activational effects of hormones in generating these differences has been reviewed extensively elsewhere $[8,9,11]$.

\section{Sex differences in synaptic transmission}

Dysfunction of a number of brain regions likely underlies the number of diverse symptoms associated with depression. Indeed, brain imaging, as well as postmortem anatomical studies have demonstrated changes in several brain areas including prefrontal cortex, cingulate cortex, hippocampus, striatum, amygdala, and thalamus [171-174]. Probing synaptic transmission in these areas has contributed to our understanding of mechanisms underlying antidepressant efficacy. Similarly, understanding sex differences in this synaptic transmission sheds light on the potential mechanisms underlying differences in antidepressant efficacy. Using the animal models described above has allowed researchers to delve deeper into the neuronal circuitry underlying depression and antidepressant response.

A number of hypotheses have been put forth in an attempt to explain the maladaptive changes found in depression. For instance, the monoamine hypothesis postulates that depression is caused by a deficiency in monoamines, yet incompletely explains depressive etiology as discussed above.

The hypotheses associated with depression appear to converge on a common factor that is a growing area of focus in understanding the pathophysiology underlying depression and antidepressant response: changes in synaptic strength. Particular focus has been dedicated to excitatory synaptic strength as there is increasing evidence to suggest that chronic stress, which induces depressive signs, weakens excitatory synaptic structure and function in multiple regions of the brain associated with depression. Conversely, antidepressants promote excitatory synaptic transmission in these same regions (Fig. 1). Differences in these synaptic changes may be associated with sex-differences in depression and antidepressant response. Though there are number of brain regions involved, reviewed in greater breadth elsewhere (e.g. [175]), we will limit our discussion to the hippocampus, prefrontal cortex, and nucleus accumbens (NAc) for the sake of brevity.

\section{Hippocampus}

The hippocampus plays critical roles in both mood regulation and higher cognitive functions. It is particularly stress sensitive due to high glucocorticoid receptor expression and its crucial role in HPAaxis feedback [176, 177]. Thus, the hippocampus is at a key intersection of neuronal mechanisms underlying depression. Patients with MDD exhibit decreased hippocampal volume, dendritic density, and spine number [178-181]. The hippocampus sends excitatory projections to regions of the brain important for reward processing including the NAc [182-184]. This is thought to be important in modulating the activity of NAc and providing contextual information associated with reward [185, 186]. Regarding stress, acute elevations of glucocorticoid levels potentiate hippocampal neurons [187], which inhibits HPA activity but also may enhance hippocampal function. However, chronically elevated glucocorticoids, as seen in chronic stress, may damage hippocampal neurons and impairs their synaptic protein expression and function [188] and consequently weaken excitatory synaptic strength [189].

In male rodents, chronic stress results in a retraction of apical dendrites of pyramidal cells in hippocampal area CA3 [190-194], decreased spine density on pyramidal cells in hippocampal area 
CA1 [195], a reduction in neurogenesis in the dentate gyrus [196198]. Several classes of antidepressants reverse the stress-induced reduction in dendritic branching $[199,200]$ and neurogenesis [201, 202] of hippocampal neurons.

The deleterious effects of stress on the hippocampus are also reflected in alterations hippocampal function. Electrophysiological studies have revealed weakening of excitatory synapses [188, 189] or deficits in synaptic plasticity [203-205] in rodent models of depression and coincide with decreased expression of GluA1 and mGluR5 [188, 189, 206]. Several classes of antidepressants have been shown to reverse these changes $[143,189,199,200]$.

The same chronic stressor that produces a reduction in dendritic complexity in males does not affect apical or basilar dendritic length of neurons in CA3 pyramidal cells of females [191], and results in altered spine morphology but no change in spine density on CA1 pyramidal cells [195]. The hippocampus expresses high levels of the receptors for estrogen and progesterone, and these hormones have a profound effect on hippocampal structure and function. Administration of exogenous estrogen or progesterone increases spine density [207, 208], and the natural variation of estrogen levels induces changes in spine density and shape in CA1 [209, 210]. These estrogen-induced spines were found to comprise increased synaptic transmission of single presynaptic inputs onto multiple postsynaptic cells, suggesting the possibility that estrogen promotes the formation of new synapses [211]. It is possible that these effects occur at least in part as a result of estrogen influence on neurotrophin signaling. Neurotrophins are involved in modulation of dendritic morphology and spine density in many brain regions including the hippocampus [212]. Inhibiting downstream neurotrophin signaling blocks the beneficial effect of estrogen on hippocampal function [213]. Conversely, BDNF administration increases serotonin receptor expression [214], as well as 5-HIAA and serotonin turnover [215].

Estrogen itself has numerous modulatory effects on synaptic transmission. It enhances presynaptic function indicated by increased neurotransmitter release [216]. Additionally, estrogen and progesterone modulate the activity of a number of different neurotransmitter systems through a number of mechanisms including interactions with receptors, transporters, and enzymes involved in synthesis [217]. While too numerous to fully discuss these interactions here, some examples include upregulation of AMPA and NMDA receptor expression, decreased $5-\mathrm{HT} 1_{\mathrm{A}}$ receptor function, and altered SERT expression and activity $[217,218]$. This is relevant for hippocampal function as excitatory synaptic strength in the hippocampus has been associated with depression and antidepressant action and serotonin signaling has been shown to be important in modulating the strength of excitatory synapses [132].

\section{Prefrontal cortex (PFC)}

The PFC is an important site at which cognitive evaluations associated with depression can influence affect and reward, such as the controllability of a stressor [219] or the pleasantness of a stimulus [220]. Patients with depression display decreased volume, spine density, and reduced activity in the PFC [221], and SSRI treatment restores normal activity levels [222-224]. These structural and functional changes are also reflected in many animal models of depression. Chronic stress results in atrophy of apical dendrites of pyramidal cells in the PFC and loss of dendritic spines [225-228], as well as downregulation of AMPA and NMDA receptor subunits and a decrease in synaptic excitation in layer $\mathrm{V}$ pyramidal cells in the PFC [229].

PFC neuron morphology appears to be sexually dimorphic at baseline. Unstressed females show decreased apical dendritic length and reduced apical branch number compared to unstressed males [230]. PFC morphology also appears to be modulated by estrogen levels as dendritic branching and spine density are decreased in ovariectomized rats and increased following estrogen treatment [231, 232].

Branch length and spine density increase in females in response to chronic stress, in contrast to males which showed a stressinduced decrease $[233,234]$. This stress-induced increase in apical dendrite length appears to be dependent on estradiol as ovariectomy prevented this effect. This sexual dimorphism in response to stress seems to be developmentally regulated as no differences are observed between juvenile male and female animals exposed to stress [235]. This further supports a role for sex hormones in modulation of neuronal circuits associated with mood regulation and parallels clinical studies demonstrating the increase in prevalence of depression in females after the onset of puberty [236]. Another study comparing the effects of chronic stress on the PFC of males and females found that while chronic stress reduced glutamatergic transmission and AMPA and NMDA receptor expression in males, females remained unaffected [237]. This was due to a protective effect of estrogen, as blocking estrogen receptors rendered females susceptible to the effects of chronic stress [237]. Taken together, these studies highlight a possible neuroprotective effect for estrogens.

Estrogen levels have been correlated with activation of the prefrontal cortex and modulation of emotional processing and fear extinction [238-240]. Estrogen therapy increases frontal cortex activation and verbal recall, a process mediated by the prefrontal cortex, in peri-menopausal and post-menopausal women [241]. However, administration of a gonadotropinreleasing hormone agonist to pre- menopausal women decreases prefrontal activation and impairs verbal memory [242], revealing a nuanced role for estrogen action in the prefrontal cortex.

The modulation of structure and activity of PFC neurons may also be in part through modulation of neurotrophin signaling in this area. Similar to hippocampus, BDNF expression in the PFC is decreased in depressed patients, as well as animal models of depression [243-245], whereas antidepressants increase BDNF expression as well as TrkB activation [246, 247]. BDNF expression also seems to be modulated by estrogen as expression was found to be reduced in the PFC of female rats during proestrus [248].

Nucleus accumbens

A key brain region implicated in the etiology of depression is the NAc a critical area for regulating reward behavior. Patients with depression have decreased NAc volume, as well as decreased activity in response to reward [249, 250]. Decreased spine density and dendritic branching were observed in some animal models of depression [251-253], however many others have reported opposing findings $[254,255]$. This may reflect differences in the models used and shed light on subtypes of depression. Accordingly, a recent study used neuroimaging biomarkers to identify subgroups found that increased NAc volume was only associated with a particular subgroup of depressed patients [256]. These human functional changes in NAc are reflected in rodent models in which decreased excitatory synaptic strength occurs in parallel to depression-like changes in behavior [257, 258]. Conversely, increased synaptic strength has been observed in other models [259]. This region incorporates excitatory information from a number of brain regions including the hippocampus and PFC, gating input from higher brain areas into subcortical reward networks. Further dissection of these inputs may provide keen insight into the neuronal circuitry underlying depression and reward regulation.

Sexual dimorphism is observed at NAc synapses. Spine density remains consistent through the rostral/caudal extent of the NAc in males, whereas a gradient exists in females with increased spine density in more caudal regions [260]. Sex differences are seen specifically at distal dendrites, with greater spine density, as well as a greater proportion of large spines in females [261]. Frequency of miniature excitatory post-synaptic currents (mEPSCs) is also 
greater in females suggesting, in conjunction with structural findings, that females have more excitatory synapses per cell in the NAC [262]. Sexual dimorphism observed in the NAc may not only be a reflection of sex differences specifically in this region but also of differences in hippocampal and PFC output.

The NAC receives dopaminergic input from the ventral tegmental area (VTA). The mesolimbic dopamine system is critical for reward processing, and rewarding stimuli is associated with dopamine release in regions like the NAc and PFC [263-265]. Sex differences in this system are thought to mediate sex differences in motivation. For instance, female rats self-administer low doses of cocaine at a faster rate as compared to males [266, 267]. Basal dopamine tone varies with the estrous cycle and parallels changes in estrogen levels with the nadir during diestrus [268]. This decreased dopamine tone is also observed in ovariectomized animals. In contrast, the basal dopamine levels in males are similar to that of females in proestrus or estrus and castration does not change these levels. Overall, basal dopamine tone is chronically higher in males than in females. Estrogen also modulates stimulated dopamine release in females [269, 270]. Taken together, this suggests that high basal dopamine levels result in downregulation of activity, such that when dopamine release is stimulated the relative increase is less in males than in females and the behavioral response is proportionally lesser, which could underlie sex differences in motivation. Yet another mechanism by which activity of the mesolimbic dopamine system differs between males and females is in dopamine receptor expression, which is greater in males as compared to females [271, 272]. Estrogen may also underlie this sexual dimorphism, as estrogen causes down-regulation of D2 receptor binding in female striatum [273].

The brain regions discussed here are profoundly interconnected, so sex differences in one area are likely to affect downstream regions. Much of the understanding we have regarding the changes in synaptic transmission in depression has been gleaned from studies in males. Further examination of synaptic transmission in females both in comparison to males at baseline, as well as in models of depression will provide key insight into understanding the pathophysiology underlying this disorder.

\section{Sex differences in pharmacokinetics}

In addition to differences in synaptic transmission, there are many other physiological factors that can lead to sex differences in antidepressant response. This has been reviewed extensively elsewhere $[4,7,10]$, so we will only briefly review some of these differences. Differences in gastric environment, slower rate of gastric emptying, and longer colonic transit times observed in women can increase the rate of absorption of antidepressants [4, $7,10]$. In addition, women have a higher percentage of adipose tissue, which can prolong the half-life of lipophilic drugs, such as trazodone and bupropion $[4,7,10]$. Differences in metabolism or clearance of antidepressants can also contribute to higher concentrations of antidepressants in women due to differences in hepatic blood flow and cytochrome P450 enzymes [4, 7, 10]. Estrogen is also a substrate for some of the same cytochrome P450 isozymes as antidepressants, and the presence of both can shift the metabolism for both $[4,7,10]$.

\section{Sex differences in side effects and compliance}

Sex differences have been reported in the side effects associated with antidepressant treatment. Women show decreased tolerability of TCAs and tend to report side effects, such as dizziness, nausea abnormal vision, constipation, and somnolence [130, 274, 275]. Men tend to report greater sexual dysfunction and urinary complaints [130, 275]. As to whether these side effects contribute to differences in compliance remains unclear. Non-compliance rates have been found to be higher for TCAs, though this was not found to be a sex-specific effect [276]. Another study found sex differences in compliance that varied by age but were not differentiated based on antidepressant type [277]. Further research into this topic as well as other sex-based differences in barriers to continuing care may yield further insight into ways to increase effective depression treatment programs.

\section{DISCUSSION}

There are clearly many differences between males and females that impact depression and antidepressant efficacy. Despite the fact depression is more common in women, the vast majority of the basic research focus has been dedicated to studying males. While this narrowed focus has aided in attempting to simplify a complex disease and thus reducing variability due to baseline sex differences, it ignores a large patient population. Because the most widely used assays have been optimized in males, this provides a significant barrier to the inclusion of females in subsequent studies. As we have discussed above, sex differences have been reported in many of the factors associated with depression including precipitation and presentation of the disorder. Therefore, it may be neither pertinent to force males and females into the same model nor practical use the same behavioral outcomes to assess them. It may, instead, be more advantageous to model depression in males and females separately focusing on endophenotypes relevant to each sex. This approach has the potential to reveal new mechanisms and biomarkers associated with depression, as well as novel targets for antidepressant development. While unraveling sex differences in depression may seem to complicate our understanding of an already complicated disease, understanding the underlying neurobiology of sex differences may be a useful means to unraveling this debilitating disease in both men and women.

\section{ACKNOWLEDGEMENTS}

We thank Adam Van Dyke for his helpful input. This work was supported by R01MH086828 (S.M.T.) and a NARSAD Young Investigator Award (T.A.L.). S.M.T. and M. D.K. are listed as a co-inventors on a patent application for the use of negative allosteric modulators of GABA-A receptors containing alpha5 subunits as fast-acting antidepressants. They have assigned their patent rights to the University of Maryland Baltimore, but will share a percentage of any royalties that may be received by the University of Maryland Baltimore. S.M.T. and M.D.K. are co-founders of a company, Asulon Therapeutics Inc., developing alpha5-selective GABA-NAMs as fast-acting antidepressants.

\section{ADDITIONAL INFORMATION}

Competing interests: The authors declare no competing interests.

Publisher's note: Springer Nature remains neutral with regard to jurisdictional claims in published maps and institutional affiliations.

\section{REFERENCES}

1. Brody DJ, Pratt LA, Hughes JP. Prevalence of depression among adults aged 20 and over: United States, 2013-2016. NCHS data brief; 2018

2. Weissman MM, Bland RC, Canino GJ, Greenwald S, Hwu HG, Joyce PR, et al. Prevalence of suicide ideation and suicide attempts in nine countries. Psychol Med. 1999;29:9-17.

3. Marcus SM, Young EA, Kerber KB, Kornstein S, Farabaugh AH, Mitchell J, et al. Gender differences in depression: findings from the STAR*D study. J Affect Disord. 2005;87:141-50.

4. Bigos KL, Pollock BG, Stankevich BA, Bies RR. Sex differences in the pharmacokinetics and pharmacodynamics of antidepressants: an updated review. Gend Med. 2009;6:522-43.

5. Dalla C, Pitychoutis PM, Kokras N, Papadopoulou-daifoti Z. Sex differences in animal models of depression and antidepressant response. Neuroscience 2009;226-33. https://doi.org/10.1111/j.1742-7843.2009.00516.x. 
6. Fiedler JL, Herrera L, Handa RJ, Program HG. Sex, stress, and mood disorders: at the intersection of adrenal and gonadal hormones. Horm Metab Res. 2012;607-18.

7. Jiawan VCR, Melgert BN. Sex differences in the pharmacokinetics of antidepressants: influence of female sex hormones and oral contraceptives. Clin Pharmacokinet. 2014;509-19. https://doi.org/10.1007/s40262-014-0145-2.

8. Palanza P. Animal models of anxiety and depression: how are females different? Neurosci Biobehav Rev. 2001;25:219-33.

9. Bale TL, Epperson CN. Sex differences and stress across the lifespan. Nat Neurosci. 2015;18:1413-20.

10. Piccinni A, Pisa U, Carlini M, Pisa U, Marazziti D, Baroni S, et al. Pharmacokinetics and pharmacodynamics of psychotropic drugs: effect of sex. CNS Spectrums. 2013. https://doi.org/10.1017/S1092852912001010.

11. Altemus M, Sarvaiya N, Neill Epperson C. Sex differences in anxiety and depression clinical perspectives. Front Neuroendocrinol. 2014;35:320-30.

12. Kessler RC, McGonagle KA, Swartz M, Blazer DG, Nelson CB. Sex and depression in the National Comorbidity Survey I: lifetime prevalence, chronicity and recurrence. J Affect Disord. 1993. https://doi.org/10.1016/0165-0327(93)90026-G.

13. Gater R, Tansella M, Korten A, Tiemens BG, Mavreas VG, Olatawura MO. Sex differences in the prevalence and detection of depressive and anxiety disorders in general health care settings: report from the World Health Organization Collaborative Study on Psychological Problems in General Health Care. Arch Gen Psychiatry. 1998;55:405-13.

14. Anderson JC, Williams S, McGee R, Silva PA. DSM-III disorders in preadolescent children-prevalence in a large sample from the general-population. Arch Gen Psychiatry. 1987;44:69-76.

15. Angold A, Costello EJ, Worthman CM. Puberty and depression: the roles of age, pubertal status and pubertal timing. Psychol Med. 1998. https://doi.org/10.1017/ S003329179700593X.

16. Wade TJ, Cairney J, Pevalin DJ. Emergence of gender differences in depression during adolescence: national panel results from three countries. J Am Acad Child Adolesc Psychiatry. 2002;41:190-8.

17. Hankin BL, Abramson LY, Moffitt TE, Silva PA, Mcgee R, Angell KE. Development of depression from preadolescence to /bung adulthood: emerging gender differences in a 10-year longitudinal study. J Abnorm Psycholoe. 1998;107:128-1.

18. Zimmerman M, Ellison W, Young D, Chelminski I, Dalrymple K. How many different ways do patients meet the diagnostic criteria for major depressive disorder? Compr Psychiatry. 2015. https://doi.org/10.1016/j. comppsych.2014.09.007.

19. Fava M, Rush AJ, Trivedi MH, Nierenberg AA, Thase ME, Sackeim HA, et al. Background and rationale for the sequenced treatment alternatives to relieve depression (STAR*D) study. Psychiatr Clin North Am. 2003;26:457-94.

20. Marcus SM, Kerber KB, Rush AJ, Wisniewski SR, Nierenberg A, Balasubramani GK, et al. Sex differences in depression symptoms in treatment-seeking adults: confirmatory analyses from the Sequenced Treatment Alternatives to Relieve Depression study. Compr Psychiatry. 2008;49:238-46.

21. Ting SA, Sullivan AF, Boudreaux ED, Miller I, Camargo CA. Trends in US emergency department visits for attempted suicide and self-inflicted injury, 19932008. Gen Hosp Psychiatry. 2012;34:557-65.

22. Doshi A, Boudreaux ED, Wang N, Pelletier AJ, Camargo CA. National study of US emergency department visits for attempted suicide and self-inflicted injury, 1997-2001. Ann Emerg Med. 2005. https://doi.org/10.1016/j. annemergmed.2005.04.018.

23. Shors TJ, Millon EM, Chang HYM, Olson RL, Alderman BL. Do sex differences in rumination explain sex differences in depression? J Neurosci Res. 2017;95:711-8.

24. Nolen-Hoeksema S, Larson J, Grayson C. Explaining the gender difference in depressive symptoms. J Pers Soc Psychol. 1999. https://doi.org/10.1037/00223514.77.5.1061.

25. Ernst C, Angst J. The Zurich Study. XII. Sex differences in depression. Evidence from longitudinal epidemiological data. Eur Arch Psychiatry Clin Neurosci. 1992;241:222-30.

26. Hankin BL. Development of sex differences in depressive and co-occurring anxious symptoms during adolescence: descriptive trajectories and potential explanations in a multiwave prospective study. J Clin Child Adolesc Psychol. 2009;38:460-72.

27. Kendler KS, Thornton LM, Prescott CA. Gender differences in the rates of exposure to stressful life events and sensitivity to their depressogenic effects. Am J Psychiatry. 2001;158:587-93.

28. Young MA, Scheftner WA, Fawcett J, Klerman GL. Gender differences in the clinical features of unipolar major depressive disorder. J Nerv Ment Dis. 1990;178:200-3.

29. Silverstein B. Gender difference in the prevalence of clinical depression: the role played by depression associated with somatic symptoms. Am J Psychiatry $1999 ; 1563$.
30. Angst J, Gamma A, Sellaro R, Zhang H, Merikangas K. Toward validation of atypical depression in the community: results of the Zurich cohort study. J Affect Disord. 2002. https://doi.org/10.1016/S0165-0327(02)00169-6.

31. Blanco C, Vesga-López O, Stewart JW, Liu S-M, Grant BF, Hasin DS. Epidemiology of major depression with atypical features: results from the National Epidemiologic Survey on Alcohol and Related Conditions (NESARC). J Clin Psychiatry. 2012;73:224-32.

32. Petersen AC, Sarigiani PA, Kennedy RE. Adolescent depression: why more girls? J Youth Adolesc. 1991;20:247-71.

33. Abramson LY, Metalsky Gl, Alloy LB. Hopelessness depression: a theory-based subtype of depression. Psychol Rev. 1989. https://doi.org/10.1037/0033295X.96.2.358

34. Hankin BL. Cognitive vulnerability-stress model of depression during adolescence: investigating depressive symptom specificity in a multi-wave prospective study. J Abnorm Child Psychol. 2008:36:999-1014.

35. Kessler RC. The effects of stressful life events on depression. Annu Rev Psychol. 1997;48:191-214.

36. Weaver ICG, Cervoni N, Champagne FA, D'Alessio AC, Sharma S, Seckl JR, et al. Epigenetic programming by maternal behavior. Nat Neurosci. 2004. https://doi. org/10.1038/nn1276.

37. Hartlage SA, Brandenburg DL, Kravitz HM. Premenstrual exacerbation of depressive disorders in a community-based sample in the United States. Psychosom Med. 2004. https://doi.org/10.1097/01.psy.0000138131.92408.b9.

38. Haley $\mathrm{CL}$, Sung SC, Rush AJ, Trivedi MH, Wisniewski SR, Luther JF, et al. The clinical relevance of self-reported premenstrual worsening of depressive symptoms in the management of depressed outpatients: a STAR*D report. J Women's Heal. 2013;22:219-29.

39. Freeman EW, Sammel MD, Boorman DW, Zhang R. ongitudinal pattern of depressive symptoms around natural menopause. JAMA Psychiatry 2014;71:36-43. https://doi.org/10.1001/jamapsychiatry.2013.2819

40. American Psychiatric Association. Diagnostic and statistical manual of mental disorders. Arlington, VA: American Psychiatric Publishing; 2013.

41. Wisner KL, Sit DKY, McShea MC, Rizzo DM, Zoretich RA, Hughes $C L$, et al. Onset Timing, Thoughts of Self-harm, and Diagnoses in Postpartum Women With Screen-Positive Depression Findings. JAMA Psychiatry 2013;70:490-8. https:// doi.org/10.1001/jamapsychiatry.2013.87

42. Barron ML, Flick LH, Cook CA, Homan SM, Campbell C. Associations between psychiatric disorders and menstrual cycle characteristics. Arch Psychiatr Nurs. 2008;22:254-65.

43. Bleil ME, Bromberger JT, Latham MD, Adler NE, Pasch LA, Gregorich SE, et al. Disruptions in ovarian function are related to depression and cardiometabolic risk during premenopause. Menopause. 2013;20:631-9.

44. Gottesman II, Gould TD. The endophenotype concept in psychiatry: Etymology and strategic intentions. Am J Psychiatry. 2003;160:636-45.

45. Gould TD, Gottesman II. Psychiatric endophenotypes and the development of valid animal models. Genes Brain Behav. 2006;5:113-9.

46. Anisman H, Merali Z. Understanding stress: characteristics and caveats. Alcohol Res Health. 1999;23:241-9.

47. Paykel ES. Stress and affective disorders in humans. Semin Clin Neuropsychiatry. 2001;6:4-11.

48. Bale TL. Stress sensitivity and the development of affective disorders. Horm Behav. 2006;50:529-33.

49. Willner $P$. The chronic mild stress (CMS) model of depression: history, evaluation and usage. Neurobiol Stress. 2017;6:78-93.

50. Konkle ATM, Baker SL, Kentner AC, Barbagallo LS, Merali Z, Bielajew C. Evaluation of the effects of chronic mild stressors on hedonic and physiological responses: sex and strain compared. Brain Res. 2003;992:227-38.

51. Baker SL, Kentner AC, Konkle ATM, Santa-Maria Barbagallo L, Bielajew C. Behavioral and physiological effects of chronic mild stress in female rats. Physiol Behav. 2006;87:314-22.

52. Atchley DPD, Weaver KL, Eckel LA. Taste responses to dilute sucrose solutions are modulated by stage of the estrous cycle and fenfluramine treatment in female rats. Physiol Behav. 2005;86:265-71.

53. Overmier JB, Seligman ME. Effects of inescapable shock upon subsequent escape and avoidable responding. J Comp Physiol Psychol. 1967;63:28-33.

54. Maier SF, Watkins LR. Stressor controllability and learned helplessness: The roles of the dorsal raphe nucleus, serotonin, and corticotropin-releasing factor. Neurosci Biobehav Rev. 2005;29:829-41.

55. Steenbergen HL, Heinsbroek RPW, Van HestA, Van de PollNE. Sex-dependent effects of inescapable shock administration on shuttlebox-escape performance and elevated plus-maze behavior. Physiol Behav. 1990;48:571-6.

56. Steenbergen HL, Farabollini F, Heinsbroek RPW. Sex-dependent effects of aversive stimulation on holeboard and elevated plus-maze behavior. Behav Brain Res. 1991;43:159-65. 
57. Mazure CM. Life stressors as risk factors in depression. Clin Psychol Sci Pract. 1998;5:291-313.

58. Hankin BL, Mermelstein R, Roesch L. Sex differences in adolescent depression: stress exposure and reactivity models. Child Dev. 2007;78:279-95.

59. Taylor SE, Klein LC, Lewis BP, Gruenewald TL, Gurung RAR, Updegraff JA. Biobehavioral responses to stress in females: tend-and-befriend, not fight-or-flight. Psychol Rev. 2000;107:411-29.

60. Hollis F, Kabbaj M. Social defeat as an animal model for depression. ILAR J. 2014;55:221-32.

61. Martinez M, Calvo-Torrent A, Pico-Alfonso MA. Social defeat and subordination as models of social stress in laboratory rodents: a review. Aggress Behav. 1998;24:241-56.

62. Takahashi A, Chung JR, Zhang S, Zhang H, Grossman Y, Aleyasin H, et al. Establishment of a repeated social defeat stress model in female mice. Sci Rep. 2017;7.

63. Haney M, Miczek KA. Ultrasounds during agonistic interactions between female rats (Rattus norvegicus). J Comp Psychol. 1993;107:373-9.

64. Kudryavtseva NN. Experience of defeat decreases the behavioural reactivity to conspecifics in the partition test. Behav Process. 1994;32:297-304.

65. Kudryavtseva NN, Bakshtanovskaya IV, Koryakina LA. Social model of depression in mice of C57BL/6J strain. Pharmacol Biochem Behav. 1991;38:315-20.

66. Poll NE, Van de, Jonge FDe, Van OyenHG, Van PeltJ. Aggressive behaviour in rats: effects of winning or losing on subsequent aggressive interactions. Behav Process. 1982;7:143-55.

67. Haney M, Maccari S, Le MoalM, Simon H, Piazza P. Social stress increases the acquisition of cocaine self-administration in male and female rats. Brain Res. 1995;698:46-52.

68. Meerlo P, Hoofdakker RHVanDen, Koolhaas JM, Daan S. Stress-induced changes in circadian rhythms of body temperature and activity in rats are not caused by pacemaker changes. J Biol Rhythms. 1997;12:80-92.

69. Meerlo P, Overkamp GJF, Daan S, Van Den HoofdakkerRH, Koolhaas JM. Changes in behaviour and body weight following a single or double social defeat in rats. Stress. 1996;1:21-32.

70. Ruis MAW, Brake JHATe, Buwalda B, Boer SFDe, Meerlo P, Korte SM, et al. Housing familiar male wildtype rats together reduces the long-term adverse behavioural and physiological effects of social defeat. Psychoneuroendocrinology. 1999;24:285-300.

71. Berton O, Aguerre S, Sarrieau A, Mormede P, Chaouloff F. Differential effects of social stress on central serotonergic activity and emotional reactivity in Lewis and spontaneously hypertensive rats. Neuroscience. 1998;82:147-59.

72. Hollis F, Duclot F, Gunjan A, Kabbaj M. Individual differences in the effect of social defeat on anhedonia and histone acetylation in the rat hippocampus. Horm Behav. 2011;59:331-7.

73. Hollis F, Wang H, Dietz D, Gunjan A, Kabbaj M. The effects of repeated social defeat on long-term depressive-like behavior and short-term histone modifications in the hippocampus in male Sprague-Dawley rats. Psychopharmacology (Berlin). 2010;211:69-77.

74. Krishnan V, Han MH, Graham DL, Berton O, Renthal W, Russo SJ, et al. Molecular adaptations underlying susceptibility and resistance to social defeat in brain reward regions. Cell. 2007;131:391-404.

75. Heinrich LM, Gullone E. The clinical significance of loneliness: a literature review. Clin Psychol Rev. 2006;26:695-718.

76. Rich AR, Scovel M. Causes of depression in college students: a cross-lagged panel correlational analysis. Psychol Rep. 1987;60:27-30.

77. Green BH, Copeland JRM, Dewey ME, Sharma V, Saunders PA, Davidson IA, et al. Risk factors for depression in elderly people: a prospective study. Acta Psychiatr Scand. 1992:86:213-7.

78. Barrot M, Wallace DL, Bolanos CA, Graham DL, Perrotti LI, Neve RL, et al. Regulation of anxiety and initiation of sexual behavior by CREB in the nucleus accumbens. Proc Natl Acad Sci. 2005;102:8357-62.

79. Wallace DL, Han MH, Graham DL, Green TA, Vialou V, Iiguez SD, et al. CREB regulation of nucleus accumbens excitability mediates social isolation-induced behavioral deficits. Nat Neurosci. 2009;12:200-9.

80. Ahmed SH, Stinus L, Le MoalM, Cador M. Social deprivation enhances the vulnerability of male Wistar rats to stressor- and amphetamine-induced behavioral sensitization. Psychopharmacology (Berlin). 1995:117:116-24.

81. Deroche V, Piazza PV, Le MoalM, Simon H. Social isolation-induced enhancement of the psychomotor effects of morphine depends on corticosterone secretion. Brain Res. 1994;640:136-9.

82. Sarkar A, Kabbaj M. Sex differences in effects of ketamine on behavior, spine density, and synaptic proteins in socially isolated rats. Biol Psychiatry. 2016;80:448-56.

83. Carrier N, Kabbaj M. Testosterone and imipramine have antidepressant effects in socially isolated male but not female rats. Horm Behav. 2012;61:678-85.
84. Haller J, Fuchs E, Halász J, Makara GB. Defeat is a major stressor in males while social instability is stressful mainly in females: towards the development of a social stress model in female rats. Brain Res Bull. 1999;50:33-39.

85. Schmidt MV, Scharf SH, Sterlemann V, Ganea K, Liebl C, Holsboer F, et al. High susceptibility to chronic social stress is associated with a depression-like phenotype. Psychoneuroendocrinology. 2010;35:635-43.

86. Schmidt MV, Sterlemann V, Ganea K, Liebl C, Alam S, Harbich D, et al. Persistent neuroendocrine and behavioral effects of a novel, etiologically relevant mouse paradigm for chronic social stress during adolescence. Psychoneuroendocrinology. 2007;32:417-29.

87. Saavedra-Rodríguez L, Feig LA. Chronic social instability induces anxiety and defective social interactions across generations. Biol Psychiatry. 2013;73:44-53.

88. Schmidt MV, Scharf SH, Liebl C, Harbich D, Mayer B, Holsboer F, et al. A novel chronic social stress paradigm in female mice. Horm Behav. 2010a;57:415-20.

89. Syed Sa, Nemeroff CB. Early life stress, mood, and anxiety disorders. Chronic Stress. 2017;1:247054701769446.

90. Ladd CO, Owens MJ, Nemeroff CB. Persistent changes in corticotropin-releasing factor neuronal systems induced by maternal deprivation. Endocrinology. 1996;137:1212-8

91. Marais L, Rensburg SJ, van, Zyl JM, van, Stein DJ, Daniels WMU. Maternal separation of rat pups increases the risk of developing depressive-like behavior after subsequent chronic stress by altering corticosterone and neurotrophin levels in the hippocampus. Neurosci Res. 2008;61:106-12.

92. Millstein RA, Holmes A. Effects of repeated maternal separation on anxiety- and depression-related phenotypes in different mouse strains. Neurosci Biobehav Rev. 2007:31:3-17.

93. O'Mahony SM, Marchesi JR, Scully P, Codling C, Ceolho AM, Quigley EMM, et al. Early life stress alters behavior, immunity, and microbiota in rats: implications for irritable bowel syndrome and psychiatric illnesses. Biol Psychiatry. 2009;65:263-7.

94. Pryce $C R$, Feldon J. Long-term neurobehavioural impact of the postnatal environment in rats: manipulations, effects and mediating mechanisms. Neurosci Biobehav Rev. 2003;27:57-71.

95. Franklin TB, Russig H, Weiss IC, Grff J, Linder N, Michalon A, et al. Epigenetic transmission of the impact of early stress across generations. Biol Psychiatry. 2010;68:408-15.

96. Leussis MP, Freund N, Brenhouse HC, Thompson BS, Andersen SL. Depressivelike behavior in adolescents after maternal separation: sex differences, controllability, and GABA. Dev Neurosci. 2012;34:210-7.

97. Viveros MP, Llorente R, López-Gallardo M, Suarez J, Bermúdez-Silva F, la Fuente $M$ De, et al. Sex-dependent alterations in response to maternal deprivation in rats. Psychoneuroendocrinology 2009;34:S217-26.

98. El KhouryA, Gruber SHM, Mørk A, Mathé AA. Adult life behavioral consequences of early maternal separation are alleviated by escitalopram treatment in a rat model of depression. Prog Neuro-Psychopharmacol Biol Psychiatry. 2006:30:535-40.

99. Lambás-Señas L, Mnie-Filali O, Certin V, Faure C, Lemoine L, Zimmer L, et al. Functional correlates for 5-HT1A receptors in maternally deprived rats displaying anxiety and depression-like behaviors. Prog Neuro-Psychopharmacol Biol Psychiatry. 2009:33:262-8.

100. Lee JH, Kim HJ, Kim JG, Ryu V, Kim BT, Kang DW, et al. Depressive behaviors and decreased expression of serotonin reuptake transporter in rats that experienced neonatal maternal separation. Neurosci Res. 2007;58:32-39.

101. Aisa B, Tordera R, Lasheras B, Del RíoJ, Ramírez MJ. Cognitive impairment associated to HPA axis hyperactivity after maternal separation in rats. Psychoneuroendocrinology. 2007;32:256-66.

102. Rüedi-Bettschen D, Pedersen EM, Feldon J, Pryce CR. Early deprivation under specific conditions leads to reduced interest in reward in adulthood in Wistar rats. Behav Brain Res. 2005;156:297-310.

103. Mourlon V, Baudin A, Blanc O, Lauber A, Giros B, Naudon L, et al. Maternal deprivation induces depressive-like behaviours only in female rats. Behav Brain Res. 2010;213:278-87.

104. Hendriksen H, Mechiel Korte S, Olivier B, Oosting RS. The olfactory bulbectomy model in mice and rat: one story or two tails? Eur J Pharmacol. 2015;753:105-13.

105. Morales-Medina JC, Dumont $Y$, Bonaventure P, Quirion R. Chronic administration of the Y2 receptor antagonist, JNJ-31020028, induced anti-depressant likebehaviors in olfactory bulbectomized rat. Neuropeptides. 2012;46:329-34.

106. Morales-Medina JC, lannitti T, Freeman A, Caldwell HK. The olfactory bulbectomized rat as a model of depression: the hippocampal pathway. Behav Brain Res. 2017:317:562-75

107. Morales-Medina JC, Juarez I, Venancio-García E, Cabrera SN, Menard C, Yu W, et al. Impaired structural hippocampal plasticity is associated with emotional and memory deficits in the olfactory bulbectomized rat. Neuroscience. 2013;236:233-43. 
108. Rinwa P, Kumar A. Quercetin suppress microglial neuroinflammatory response and induce antidepressent-like effect in olfactory bulbectomized rats. Neuroscience. 2013;255:86-98.

109. Kelly JP, Wrynn AS, Leonard BE. The olfactory bulbectomized rat as a model of depression: an update. Pharmacol Ther. 1997;74:299-316.

110. Song $C$, Leonard BE. The olfactory bulbectomised rat as a model of depression. Neurosci Biobehav Rev. 2005;29:627-47.

111. Belcheva I, Ivanova M, Tashev R, Belcheva S. Differential involvement of hippocampal vasoactive intestinal peptide in nociception of rats with a model of depression. Peptides 2009;30:1497-1501.

112. Wang W, Qi WJ, Xu Y, Wang JY, Luo F. The differential effects of depression on evoked and spontaneous pain behaviors in olfactory bulbectomized rats. Neurosci Lett 2010;472:143-7.

113. Stock HS, Ford K, Wilson MA. Gender and gonadal hormone effects in the olfactory bulbectomy animal model of depression. Pharmacol Biochem Behav. 2000;67:183-91.

114. Cryan JF, Mombereau C. In search of a depressed mouse: utility of models for studying depression-related behavior in genetically modified mice. Mol Psychiatry. 2004;9:326-57.

115. Overstreet DH, Friedman E, Mathé AA, Yadid G. The Flinders Sensitive Line rat: a selectively bred putative animal model of depression. Neurosci Biobehav Rev. 2005;29:739-59.

116. Kokras N, Antoniou K, Dalla C, Bekris S, Xagoraris M. Sex-related differential response to clomipramine treatment in a rat model of depression. J. Psychopharmacol. 2009;23:945-56.

117. Disner SG, Beevers CG, Haigh EAP, Beck AT. Neural mechanisms of the cognitive model of depression. Nat Rev Neurosci. 2011;12:467-77.

118. Johnson DP, Whisman MA. Gender differences in rumination: a meta-analysis. Pers Individ Dif. 2013;55:367-74.

119. Harding EJ, Paul ES, Mendl M. Animal behaviour: cognitive bias and affective state. Nature. 2004:427:312-312.

120. Bondi CO, Rodriguez G, Gould GG, Frazer A, Morilak DA. Chronic unpredictable stress induces a cognitive deficit and anxiety-like behavior in rats that is prevented by chronic antidepressant drug treatment. Neuropsychopharmacology. 2008;33:320-31.

121. Barker TH, Bobrovskaya L, Howarth GS, Whittaker AL. Female rats display fewer optimistic responses in a judgment bias test in the absence of a physiological stress response. Physiol Behav. 2017;173:124-31.

122. Brown GR, Cullum P, Martin S, Healy SD. Sex differences in performance on a cognitive bias task in Norway rats. Behav Process. 2016;133:52-55.

123. Beyer S. Gender differences in self-perception and negative recall biases. Sex Roles. 1998;38:103-33.

124. Lopez-Munoz F, Alamo C. Monoaminergic neurotransmission: the history of the discovery of antidepressants from 1950s until today. Curr Pharm Des. 2009;15:1563-86.

125. Gillman PK. Tricyclic antidepressant pharmacology and therapeutic drug interactions updated. Br J Pharmacol. 2007;151:737-48.

126. Thanacoody HKR, Thomas SHL. Tricyclic antidepressant poisoning: cardiovascular toxicity. Toxicol Rev. 2005;24:205-14.

127. Grunebaum MF, Ellis SP, Li S, Oquendo MA, Mann JJ. Antidepressants and suicide risk in the United States, 1985-99. J Clin Psychiatry. 2004;65:1456-62.

128. White N, Litovitz T, Clancy C. Suicidal antidepressant overdoses: a comparative analysis by antidepressant type. J Med Toxicol. 2008;4:238-50.

129. Khan A, Brodhead AE, Schwartz KA, Kolts RL, Brown WA. Sex differences in antidepressant response in recent antidepressant clinical trials. J Clin Psychopharmacol. 2005;25:318-24.

130. Kornstein SG, Schatzberg AF, Thase ME, Yonkers KA, McCullough JP, Keitner GI, et al. Gender differences in treatment response to sertraline versus imipramine in chronic depression. Am J Psychiatry. 2000;157:1445-52.

131. Moore TJ, Mattison DR. Adult utilization of psychiatric drugs and differences by sex, age, and race. JAMA Intern Med. 2017:177:274-5.

132. Thompson SM, Kallarackal AJ, Kvarta MD, Dyke AM Van, Legates TA, Cai X. An excitatory synapse hypothesis of depression. Trends Neurosci 2005;1-16. https://doi.org/10.1016/j.tins.2015.03.003.

133. Gartlehner G, Hansen R, Morgan L, Thaler K, Lux L, Noord M Van, et al. (2011). Second-Generation Antidepressants in the Pharmacologic Treatment of Adult Depression: An Update of the 2007 Comparative Effectiveness Review. AHRQ Publ No 12-EHC012-EF 1-954 AHRQ Publication No. 12-EHC012-EF.

134. Gaynes BN, Warden D, Trivedi MH, Wisniewski SR, Fava M, Rush aJ. What did $\mathrm{STAR}^{*} \mathrm{D}$ teach us? Results from a large-scale, practical, clinical trial for patients with depression. Psychiatr Serv. 2009;60:1439-45.

135. Berman R, Cappiello A, Anand A. Antidepressant effects of ketamine in depressed patients. Biol. Psychiatry. 2000;3223:351-4.
136. Price RB, Nock MK, Charney DS, Mathew SJ. Effects of intravenous ketamine on explicit and implicit measures of suicidality in treatment-resistant depression. Biol Psychiatry. 2009;66:522-6.

137. Zarate CA, Singh JB, Carlson P, Brutsche N, Ameli R, Luckenbaugh DA, et al. A randomized trial of an $\mathrm{N}$-methyl-D-aspartate antagonist in treatment-resistant major depression. Arch Gen Psychiatry. 2006;63:856-64.

138. Autry AE, Adachi M, Nosyreva E, Na ES, Los MF, Cheng $P$, et al. NMDA receptor blockade at rest triggers rapid behavioural antidepressant responses. Nature. 2011;475:91-95.

139. Li N, Lee B, Liu R-J, Banasr M, Dwyer JM, Iwata M, et al. mTOR-dependent synapse formation underlies the rapid antidepressant effects of NMDA antagonists. Science. 2010;329:959-64.

140. Voleti B, Navarria A, Liu R, Banasr M, Li N, Terwilliger R. et al. Scopolamine rapidly increases mammalian target of rapamycin complex 1 signaling, synaptogenesis, and antidepressant behavioral responses. Biol Psychiatry. 2013;74:742-9.

141. Zanos P, Moaddel R, Morris PJ, Georgiou P, Fischell J, Elmer Gl, et al. NMDAR inhibition-independent antidepressant actions of ketamine metabolites. Nature. 2016;533:481-6.

142. Atack JR, Maubach KA, Wafford KA, Connor DO, Rodrigues AD, Evans DC, et al. In vitro and in vivo properties of 3-tert-butyl-7-(5-methylisoxazol- selective inverse agonist. Pharmacology. 2009;331:470-84.

143. Fischell J, Dyke AMVan, Kvarta MD, LeGates TA, Thompson SM. Rapid antidepressant action and restoration of excitatory synaptic strength after chronic stress by negative modulators of alpha5-containing GABAA receptors. Neuropsychopharmacology. 2015;40:1-11.

144. Zanos P, Nelson ME, Highland JN, Krimmel SR. A negative allosteric modulator for $\_5$ subunit- containing GABA receptors exerts a rapid and persistent antidepressant-like action without the side effects of the NMDA receptor antagonist ketamine in mice. eNeuro. 2017;4:1-11.

145. Kellner CH, Knapp RG, Petrides G, Rummans TA, Husain MM, Rasmussen K, et al. Continuation electroconvulsive therapy vs pharmacotherapy for relapse prevention in major depression: a multisite study from the consortium for research in electroconvulsive therapy (CORE). Arch Gen Psychiatry. 2006;63:1337-44.

146. Sackeim HA, Haskett RF, Mulsant BH, Thase ME, Mann JJ, Pettinati HM, et al. Continuation pharmacotherapy in the prevention of relapse following electroconvulsive therapy: a randomized controlled trial. JAMA. 2001;285:1299-307.

147. George MS, Lisanby SH, Sackeim HA. Transcranial magnetic stimulation: applications in neuropsychiatry. Arch Gen Psychiatry. 1999;56:300-11.

148. Burt T, Lisanby SH, Sackeim HA. Neuropsychiatric applications of transcranial magnetic stimulation: a meta analysis. Int J Neuropsychopharmacol. 2002;5:73-103.

149. George MS, Lisanby SH, Avery D, McDonald WM, Durkalski V, Pavlicova M, et al. Daily left prefrontal transcranial magnetic stimulation therapy for major depressive disorder: a sham-controlled randomized trial. Arch Gen Psychiatry. 2010;67:507-16.

150. Mayberg HS. Targeted electrode-based modulation of neural circuits for depression. J Clin Invest. 2009;119:717-25.

151. Malone Da, Dougherty DD, Rezai AR, Carpenter LL, Friehs GM, Eskandar EN, et al. Deep brain stimulation of the ventral capsule/ventral striatum for treatmentresistant depression. Biol Psychiatry. 2009;65:267-75.

152. Manohar $H$, Subramanian $K$, Menon $V$, Kattimani $S$. Does gender influence electroconvulsive therapy sessions required across psychiatric diagnoses? A 5 year experience from a single center. J Neurosci Rural Pract. 2017:8:427.

153. Alino JJ, Jimenez JL, Flores SC, Alcocer MI. Efficacy of transcranial magnetic stimulation (TMS) in depression: naturalistic study. Actas Esp Psiquiatr. 2010;38:87-93

154. Huang CC, Wei IH, Chou YH, Su TP. Effect of age, gender, menopausal status, and ovarian hormonal level on rTMS in treatment-resistant depression. Psychoneuroendocrinology. 2008;33:821-31.

155. Raskin A. Age-sex differences in response to antidepressant drugs. J Nerv Ment Dis. 1974;159:120-30.

156. Frank E, Carpenter LL, Kupfer DJ. Sex differences in recurrent depression: are there any that are significant? Am J Psychiatry. 1988;145:41-45.

157. Haykal RF, Akiskal HS. The long-term outcome of dysthymia in private practice: clinical features, temperament, and the art of management. J Clin Psychiatry. 1999;60:508-18.

158. Berlanga $C$, Flores-Ramos $M$. Different gender response to serotonergic and noradrenergic antidepressants. A comparative study of the efficacy of citalopram and reboxetine. J Affect Disord. 2006;95:119-23.

159. Kim JM, Kim SW, Stewart R, Kim SY, Yoon JS, Jung SW, et al. Predictors of 12week remission in a nationwide cohort of people with depressive disorders: the CRESCEND study. Hum Psychopharmacol. 2011;26:41-50.

160. Thase ME, Entsuah $\mathrm{R}$, Cantillon M, Kornstein SG. Relative antidepressant efficacy of venlafaxine and SSRIs: sex-age interactions. J Women's Heal. 2005;14:609-16. 
161. Keers R, Aitchison KJ. Gender differences in antidepressant drug response. 2010;22:485-500.

162. Pande AC, Birkett M, Fechner-Bates S, Haskett RF, Greden JF. Fluoxetine versus phenelzine in atypical depression. Biol Psychiatry. 1996;40:1017-20.

163. Altshuler LL, Bauer M, Frye MA, Gitlin MJ, Mintz J, Szuba MP, et al. Does thyroid supplementation accelerate tricyclic antidepressant response? A review and meta-analysis of the literature. Am J Psychiatry. 2001;158:1617-22.

164. Coppen A, Bailey J. Enhancement of the antidepressant action of fluoxetine by folic acid: a randomised, placebo controlled trial. J Affect Disord. 2000;60:121-30.

165. Carrier N, Kabbaj M. Sex differences in the antidepressant-like effects of ketamine. Neuropharmacology. 2013;70:27-34.

166. Franceschelli A, Sens J, Herchick S, Thelen C, Pitychoutis PM. Sex differences in the rapid and the sustained antidepressant-like effects of ketamine in stressnaïve and "depressed" mice exposed to chronic mild stress. Neuroscience. 2015;290:49-60.

167. Saland SK, Schoepfer KJ, Kabbaj M. Hedonic sensitivity to low-dose ketamine is modulated by gonadal hormones in a sex-dependent manner. Sci Rep. 2016;6:1-16.

168. Kokras N, Antoniou K, Mikail HG, Kafetzopoulos V, Papadopoulou-daifoti Z, Dalla C. Neuropharmacology Forced swim test: what about females? Neuropharmacology. 2015;99:408-21.

169. Stoffel EC, Craft RM. Ovarian hormone withdrawal-induced "depression" in female rats. Physiol Behav. 2004;83:505-13.

170. Koss Wa, Einat H, Schloesser RJ, Manji HK, Rubinow DR. Estrogen effects on the forced swim test differ in two outbred rat strains. Physiol Behav. 2012;106:81-86.

171. Manji HK, Drevets WC, Charney DS. The cellular neurobiology of depression. Nat Med. 2001;7:541-7.

172. Rajkowska G. Histopathology of the prefrontal cortex in major depression: what does it tell us about dysfunctional monoaminergic circuits? Prog Brain Res. 2000;126:397-412.

173. Zhu MY, Klimek V, Dilley GE, Haycock JW, Stockmeier C, Overholser JC, et al. Elevated levels of tyrosine hydroxylase in the locus coeruleus in major depression. Biol Psychiatry. 1999;46:1275-86.

174. Drevets WC. Neuroimaging and neuropathological studies of depression: implications for the cognitive-emotional features of mood disorders. Curr Opin Neurobiol. 2001;11:240-9.

175. Russo S, Nestler E. The brain reward circuitry in mood disorders. Nat Rev Neurosci. 2013;14:609-25.

176. McEwen BS, Weiss JM, Schwartz LS. Selective retention of corticosterone by limbic structures in rat brain. Nature. 1968;220:911-2.

177. Myers B, McKlveen JM, Herman JP. Neural regulation of the stress response: the many faces of feedback. Cell Mol Neurobiol. 2012;32:683-94.

178. Sheline YI, Sanghavi M, Mintun MA, Gado MH. Depression duration but not age predicts hippocampal volume loss in medically healthy women with recurrent major depression. J Neurosci. 1999;19:5034-43.

179. Soetanto A, Wilson RS, Talbot K, Un A, Schneider JA, Sobiesk M, et al. Association of anxiety and depression with microtubule-associated protein 2- and synaptopodin-immunolabeled dendrite and spine densities in hippocampal CA3 of older humans. Arch Gen Psychiatry. 2010;67:448-57.

180. Bora E, Fornito A, Pantelis C, Yücel M. Gray matter abnormalities in Major Depressive Disorder: a meta-analysis of voxel based morphometry studies. J Affect Disord. 2012;138:9-18.

181. Bremner JD, Narayan M, Anderson ER, Staib LH, Miller HL, Charney DS. Hippocampal volume reduction in major depression. Am J Psychiatry. 2000;157:115-8.

182. Kelley SP, Mittleman G. Effects of hippocampal damage on reward threshold and response rate during self-stimulation of the ventral tegmental area in the rat. Behav Brain Res. 1999;99:133-41.

183. Boulenguez $P$. Modulation of dopamine release in the nucleus accumbens by 5HTIB agonists: Involvement of the hippocampo-accumbens pathway. Neuropharmacology. 1996;35:1521-9.

184. Floresco SB, Todd CL, Grace AA. Glutamatergic afferents from the hippocampus to the nucleus accumbens regulate activity of ventral tegmental area dopamine neurons. J Neurosci. 2001:21:4915-22.

185. O'Donnell P, Grace AA. Synaptic interactions among excitatory afferents to nucleus accumbens neurons: hippocampal gating of prefrontal cortical input. J Neurosci. 1995;15:3622-39.

186. Goto $\mathrm{Y}$, O'Donnell P. Synchronous activity in the hippocampus and nucleus accumbens in vivo. J Neurosci. 2001;21:RC131.

187. Whitehead G, Jo J, Hogg EL, Piers T, Kim D-H, Seaton G, et al. Acute stress causes rapid synaptic insertion of $\mathrm{Ca} 2+$-permeable AMPA receptors to facilitate longterm potentiation in the hippocampus. Brain. 2013;136:3753-65.
188. Kvarta MD, Bradbrook KE, Dantrassy HM, Bailey AM, Thompson SM. Corticosterone mediates the synaptic and behavioral effects of chronic stress at rat hippocampal temporoammonic synapses. J Neurophysiol. 2015;114:1713-24.

189. Kallarackal AJ, Kvarta MD, Cammarata E, Jaberi L, Cai X, Bailey AM, et al. Chronic stress induces a selective decrease in AMPA receptor-mediated synaptic excitation at hippocampal temporoammonic-CA1 synapses. J Neurosci. 2013;33:15669-74.

190. Conrad CD, LeDoux JE, Magariños AM, McEwen BS. Repeated restraint stress facilitates fear conditioning independently of causing hippocampal CA3 dendritic atrophy. Behav Neurosci. 1999;113:902-13.

191. Galea La, McEwen B, Tanapat P, Deak T, Spencer R, Dhabhar F. Sex differences in dendritic atrophy of CA3 pyramidal neurons in response to chronic restraint stress. Neuroscience. 1997;81:689-97.

192. Magariños AM, McEwen BS. Stress-induced atrophy of apical dendrites of hippocampal CA3C neurons: Comparison of stressors. Neuroscience. 1995;69:83-88.

193. Magariños AM, McEwen BS, Flügge G, Fuchs E. Chronic psychosocial stress causes apical dendritic atrophy of hippocampal CA3 pyramidal neurons in subordinate tree shrews. J Neurosci. 1996;16:3534-40.

194. Watanabe Y, Gould E, McEwen BS. Stress induces atrophy of apical dendrites of hippocampal CA3 pyramidal neurons. Brain Res. 1992;588:341-5.

195. McLaughlin KJ, Baran SE, Wright RL, Conrad CD. Chronic stress enhances spatial memory in ovariectomized female rats despite CA3 dendritic retraction: possible involvement of CA1 neurons. Neuroscience. 2005;135:1045-54.

196. Gould E, McEwen BSS, Tanapat P, Galea LAM A, Fuchs E. Neurogenesis in the dentate gyrus of the adult tree shrew is regulated by psychosocial stress and NMDA receptor activation. J Neurosci. 1997;17:2492-8.

197. Malberg JE, Duman RS. Cell proliferation in adult hippocampus is decreased by inescapable stress: reversal by fluoxetine treatment. Neuropsychopharmacology. 2003;28:1562-71.

198. Pham K, Nacher J, Hof PR, McEwen BS. Repeated restraint stress suppresses neurogenesis and induces biphasic PSA-NCAM expression in the adult rat dentate gyrus. Eur J Neurosci. 2003;17:879-86.

199. Kuroda Y, McEwen BS. Effect of chronic restraint stress and tianeptine on growth factors, growth-associated protein-43 and microtubule-associated protein 2 mRNA expression in the rat hippocampus. Brain Res Mol Brain Res. 1998;59:35-39.

200. Norrholm SD, Ouimet CC. Altered dendritic spine density in animal models of depression and in response to antidepressant treatment. Synapse. 2001;42:151-63.

201. Duman RS, Nakagawa S, Malberg JE. Regulation of adult neurogenesis by antidepressant treatment. Neuropsychopharmacology. 2001;25:836-44.

202. Malberg JE, Eisch AJ, Nestler EJ, Duman RS. Chronic antidepressant treatment increases neurogenesis in adult rat hippocampus. J Neurosci. 2000;20:9104-10.

203. Cai X, Kallarackal AJ, Kvarta MD, Goluskin S, Gaylor K, Bailey AM, et al. Local potentiation of excitatory synapses by serotonin and its alteration in rodent models of depression. Nat Neurosci. 2013;16:464-72.

204. Holderbach R, Clark K, Moreau J-L, Bischofberger J, Normann C. Enhanced longterm synaptic depression in an animal model of depression. Biol Psychiatry. 2007;62:92-100.

205. LeGates Ta, Altimus $\mathrm{CM}$, Wang $\mathrm{H}$, Lee $\mathrm{H}-\mathrm{K}$, Yang $\mathrm{S}$, Zhao $\mathrm{H}$, et al. Aberrant light directly impairs mood and learning through melanopsin-expressing neurons. Nature. 2012;491:594-8.

206. Iyo AH, Feyissa AM, Chandran A, Austin MC, Regunathan S, Karolewicz B. Chronic corticosterone administration down-regulates metabotropic glutamate receptor 5 protein expression in the rat hippocampus. Neuroscience. 2010;169:1567-74.

207. Li C, Brake WG, Romeo RD, Dunlop JC, Gordon M, Buzescu R, et al. Estrogen alters hippocampal dendritic spine shape and enhances synaptic protein immunoreactivity and spatial memory in female mice. Proc Natl Acad Sci. 2004;101:2185-90.

208. Woolley CS, Weiland NG, McEwen BS, Schwartzkroin PA. Estradiol increases the sensitivity of hippocampal CA1 pyramidal cells to NMDA receptor-mediated synaptic input: correlation with dendritic spine density. J Neurosci. 1997;17:1848-59.

209. González-Burgos I, Alejandre-Gómez M, Cervantes M. Spine-type densities of hippocampal CA1 neurons vary in proestrus and estrus rats. Neurosci Lett. 2005;379:52-54.

210. Gould E, Woolley CS, Frankfurt M, McEwen BS. Gonadal steroids regulate dendritic spine density in hippocampal pyramidal cells in adulthood. J Neurosci. 1990;10:1286-91.

211. Yankova M, Hart Sa, Woolley CS. Estrogen increases synaptic connectivity between single presynaptic inputs and multiple postsynaptic CA1 pyramidal cells: a serial electron-microscopic study. Proc Natl Acad Sci USA. 2001; 98:3525-30. 
212. Tyler WJ. From acquisition to consolidation: on the role of brain-derived neurotrophic factor signaling in hippocampal-dependent learning. Learn Mem. 2002;9:224-37.

213. Fernandez SM, Lewis MC, Pechenino AS, Harburger LL, Orr PT, Gresack JE, et al. Estradiol-induced enhancement of object memory consolidation involves hippocampal extracellular signal-regulated kinase activation and membranebound estrogen receptors. J Neurosci. 2008;28:8660-7.

214. Naumenko VS, Kondaurova EM, Bazovkina DV, Tsybko AS, Tikhonova MA, Kulikov AV, et al. Effect of brain-derived neurotrophic factor on behavior and key members of the brain serotonin system in genetically predisposed to behavioral disorders mouse strains. Neuroscience. 2012;214:59-67.

215. Siuciak JA, Boylan C, Fritsche M, Altar CA, Lindsay RM. BDNF increases monoaminergic activity in rat brain following intracerebroventricular or intraparenchymal administration. Brain Res. 1996;710:11-20.

216. Yokomaku D, Numakawa T, Numakawa Y, Suzuki S, Matsumoto T, Adachi N et al. Estrogen enhances depolarization-induced glutamate release through activation of phosphatidylinositol 3-kinase and mitogen-activated protein kinase in cultured hippocampal neurons. Mol Endocrinol. 2003;17:831-44.

217. Barth C, Villringer A, Sacher J. Sex hormones affect neurotransmitters and shape the adult female brain during hormonal transition periods. Front Neurosci. 2015;9:1-20.

218. Borrow AP, Cameron NM. Estrogenic mediation of serotonergic and neurotrophic systems: implications for female mood disorders. Prog NeuroPsychopharmacol Biol Psychiatry. 2014;54:13-25.

219. Amat J, Baratta MV, Paul E, Bland ST, Watkins LR, Maier SF. Medial prefrontal cortex determines how stressor controllability affects behavior and dorsal raphe nucleus. Nat Neurosci. 2005;8:365-71.

220. Berridge KC, Kringelbach ML. Neuroscience of affect: brain mechanisms of pleasure and displeasure. Curr Opin Neurobiol. 2013;23:294-303.

221. Licznerski P, Duman RS. Remodeling of axo-spinous synapses in the pathophysiology and treatment of depression. Neuroscience 2013;251:33-50.

222. Fales CL, Barch DM, Rundle MM, Mintun MA, Mathews J, Snyder AZ, et al. Antidepressant treatment normalizes hypoactivity in dorsolateral prefrontal cortex during emotional interference processing in major depression. J Affect Disord. 2009:112:206-11.

223. Kennedy SH, Evans KR, Krüger S, Mayberg HS, Meyer JH, McCann S, et al. Changes in regional brain glucose metabolism measured with positron emission tomography after paroxetine treatment of major depression. Am J Psychiatry. 2001;158:899-905

224. Smith DF, Jakobsen S. Molecular neurobiology of depression: PET findings on the elusive correlation with symptom severity. Front Psychiatry. 2013;4.

225. Brown SM, Henning S, Wellman CL. Mild, short-term stress alters dendritic morphology in rat medial prefrontal cortex. Cereb Cortex. 2005;15:1714-22.

226. Cook SC, Wellman CL. Chronic stress alters dendritic morphology in rat medial prefrontal cortex. J Neurobiol. 2004;60:236-48.

227. Liston C, Miller MM, Goldwater DS, Radley JJ, Rocher AB, Hof PR, et al. Stressinduced alterations in prefrontal cortical dendritic morphology predict selective impairments in perceptual attentional set-shifting. J Neurosci. 2006;26:7870-4.

228. Radley JJ, Rocher AB, Rodriguez A, Ehlenberger DB, Dammann M, McEwen BS, et al. Repeated stress alters dendritic spine morphology in the rat medial prefrontal cortex. J Comp Neurol. 2008;507:1141-50.

229. Yuen EY, Wei J, Liu W, Zhong P, Li X, Yan Z. Repeated stress causes cognitive impairment by suppressing glutamate receptor expression and function in prefrontal cortex. Neuron. 2012;73:962-77.

230. Garrett JE, Wellman CL. Chronic stress effects on dendritic morphology in medial prefrontal cortex: sex differences and estrogen dependence. Neuroscience. 2009a;162:195-207.

231. Hao J, Rapp PR, Janssen WGM, Lou W, Lasley BL, Hof PR, et al. Interactive effects of age and estrogen on cognition and pyramidal neurons in monkey prefrontal cortex. Proc Natl Acad Sci USA. 2007;104:11465-70.

232. Luine V, Attalla S, Mohan G, Costa A, Frankfurt M. Dietary phytoestrogens enhance spatial memory and spine density in the hippocampus and prefrontal cortex of ovariectomized rats. Brain Res. 2006;1126:183-7.

233. Garrett JE, Wellman CL. Chronic stress effects on dendritic morphology in medial prefrontal cortex: sex differences and estrogen dependence. Neuroscience. 2009b;162:195-207.

234. Shansky RM, Hamo C, Hof PR, Lou W, McEwen BS, Morrison JH. Estrogen promotes stress sensitivity in a prefrontal cortex-amygdala pathway. Cereb Cortex. 2010;20:2560-7.

235. Eiland L, Ramroop J, Hill MN, Manley J, McEwen BS. Chronic juvenile stress produces corticolimbic dendritic architectural remodeling and modulates emotional behavior in male and female rats. Psychoneuroendocrinology. 2013;37:39-47.

236. Emslie GJ, Ryan ND, Wagner KD. Major depressive disorder in children and adolescents: clinical trial design and antidepressant efficacy. J Clin Psychiatry. 2005;66(Suppl 7):14-20.
237. Wei J, Yuen EY, Liu W, Li X, Zhong P, Karatsoreos IN, et al. Estrogen protects against the detrimental effects of repeated stress on glutamatergic transmission and cognition. Mol Psychiatry. 2014;19:588-98.

238. Amin Z, Epperson CN, Constable RT, Canli T. Effects of estrogen variation on neural correlates of emotional response inhibition. Neuroimage. 2006;32:457-64.

239. Konrad C, Engelien A, Schöning S, Zwitserlood P, Jansen A, Pletziger E, et al. The functional anatomy of semantic retrieval is influenced by gender, menstrual cycle, and sex hormones. J Neural Transm. 2008;115:1327-37.

240. Zeidan MA, Igoe SA, Linnman C, Vitalo A, Levine JB, Klibanski A, et al. Estradiol modulates medial prefrontal cortex and amygdala activity during fear extinction in women and female rats. Biol Psychiatry. 2011;70:920-7.

241. Joffe H, Hall JE, Gruber S, Sarmiento IA, Cohen LS, Yurgelun-Todd D, et al. Estrogen therapy selectively enhances prefrontal cognitive processes: a randomized, double-blind, placebo-controlled study with functional magnetic resonance imaging in perimenopausal and recently postmenopausal women. Menopause. 2006;13:411.

242. Craig MC, Fletcher PC, Daly EM, Rymer J, Cutter WJ, Brammer M, et al. Gonadotropin hormone releasing hormone agonists alter prefrontal function during verbal encoding in young women. Psychoneuroendocrinology. 2007; 32:1116-27.

243. Burton CL, Chatterjee D, Chatterjee-Chakraborty M, Lovic V, Grella SL, Steiner M, et al. Prenatal restraint stress and motherless rearing disrupts expression of plasticity markers and stress-induced corticosterone release in adult female Sprague-Dawley rats. Brain Res. 2007;1158:28-38.

244. Castrén E. Neurotrophic effects of antidepressant drugs. Curr Opin Pharmacol. 2004:4:58-64.

245. Dwivedi Y, Rizavi HS, Zhang H, Mondal AC, Roberts RC, Conley RR, et al. Neurotrophin receptor activation and expression in human postmortem brain: effect of suicide. Biol Psychiatry. 2009;65:319-28.

246. Prickaerts J, Moechars D, Cryns K, Lenaerts I, Craenendonck H, van, Goris I, et al. Transgenic mice overexpressing glycogen synthase kinase 3beta: a putative model of hyperactivity and mania. J Neurosci. 2006;26:9022-9.

247. Saarelainen T, Hendolin P, Lucas G, Koponen E, Sairanen M, MacDonald E, et al. Activation of the TrkB neurotrophin receptor is induced by antidepressant drugs and is required for antidepressant-induced behavioral effects. J Neurosci. 2003;23:349-57.

248. Cavus I, Duman RS. Influence of estradiol, stress, and 5-HT2A agonist treatment on brain-derived neurotrophic factor expression in female rats. Biol Psychiatry. 2003;54:59-69.

249. Pizzagalli Da, Holmes AJ, Dillon DG, Goetz EL, Birk JL, Bogdan R, et al. Reduced caudate and nucleus accumbens response to rewards in unmedicated subjects with major depressive disorder. Am J Psychiatry. 2009;166:702-10.

250. Wacker J, Dillon DG, Pizzagalli DA. The role of the nucleus accumbens and rostral anterior cingulate cortex in anhedonia: Integration of resting $\mathrm{EEG}, \mathrm{fMRI}$ and volumetric techniques. Neuroimage. 2009;46:327-37.

251. Martínez-Téllez Rl, Hernández-Torres E, Gamboa C, Flores G. Prenatal stress alters spine density and dendritic length of nucleus accumbens and hippocampus neurons in rat offspring. Synapse. 2009;63:794-804.

252. Monroy E, Hernández-Torres E, Flores G. Maternal separation disrupts dendritic morphology of neurons in prefrontal cortex, hippocampus, and nucleus accumbens in male rat offspring. J Chem Neuroanat. 2010;40:93-101.

253. Morales-Medina JC, Sanchez F, Flores G, Dumont Y, Quirion R. Morphological reorganization after repeated corticosterone administration in the hippocampus, nucleus accumbens and amygdala in the rat. J Chem Neuroanat. 2009;38:266-72.

254. Bessa JM, Morais M, Marques F, Pinto L, Palha JA, OFX Almeida, et al. Stressinduced anhedonia is associated with hypertrophy of medium spiny neurons of the nucleus accumbens. Transl Psychiatry. 2013:3:e266-7.

255. Qiao H, Li MX, Xu C, Bin ChenH, An SC, Ma XM. Dendritic spines in depression: what we learned from animal models. Neural Plast. 2016;2016:20-24.

256. Abdallah CG, Jackowski A, Salas R, Gupta S, Sato JR, Mao X, et al. The nucleus accumbens and ketamine treatment in major depressive disorder. Neuropsychopharmacology. 2017:42:1739-46.

257. Francis TC, Chandra R, Friend DM, Finkel E, Dayrit G, Miranda J, et al. Nucleus accumbens medium spiny neuron subtypes mediate depression-related outcomes to social defeat stress. Biol Psychiatry. 2015;77:212-22.

258. Lim BK, Huang KW, Grueter BA, Rothwell PE, Malenka RC. Anhedonia requires MC4R-mediated synaptic adaptations in nucleus accumbens. Nature. 2012;487:183-9.

259. Campioni MR, Xu M, McGehee DS. Stress-induced changes in nucleus accumbens glutamate synaptic plasticity. J Neurophysiol. 2009;101:3192-8.

260. Wissman AM, May RM, Woolley CS. Ultrastructural analysis of sex differences in nucleus accumbens synaptic connectivity. Brain Struct Funct. 2012; 217:181-90.

261. Forlano PM, Woolley CS. Quantitative analysis of pre-and postsynaptic sex differences in the nucleus accumbens. J Comp Neurol. 2010;518:1330-48. 
262. Wissman AM, McCollum AF, Huang G-Z, Nikrodhanond AA, Woolley CS. Sex differences and effects of cocaine on excitatory synapses in the nucleus accumbens. Neuropharmacology. 2011;61:217-27.

263. Bassareo V, Chiara G, Di. Differential influence of associative and nonassociative learning mechanisms on the responsiveness of prefrontal and accumbal dopamine transmission to food stimuli in rats fed ad libitum. J Neurosci. 1997;17:851-61.

264. Di ChiaraG, Imperato A. Drugs abused by humans preferentially increase synaptic dopamine concentrations in the mesolimbic system of freely moving rats. Proc Natl Acad Sci. 1988;85:5274-8.

265. Fiorino DF, Phillips AG. Facilitation of sexual behavior and enhanced dopamine efflux in the nucleus accumbens of male rats after D-amphetamine-induced behavioral sensitization. J Neurosci. 1999;19:456-63.

266. Davis BA, Clinton SM, Akil H, Becker JB. The effects of novelty-seeking phenotypes and sex differences on acquisition of cocaine self-administration in selectively bred high-responder and low-responder rats. Pharmacol Biochem Behav. 2008;90:331-8.

267. Lynch WJ, Arizzi MN, Carroll ME. Effects of sex and the estrous cycle on regulation of intravenously self-administered cocaine in rats. Psychopharmacology (Berlin). 2000;152:132-9.

268. Xiao L, Becker JB. Quantitative microdialysis determination of extracellular striatal dopamine concentration in male and female rats: effects of estrous cycle and gonadectomy. Neurosci Lett. 1994;180:155-8.

269. Becker JB. Direct effect of 17 beta-estradiol on striatum: sex differences in dopamine release. Synapse. 1990;5:157-64.
270. Becker JB. Estrogen rapidly potentiates amphetamine-induced striatal dopamine release and rotational behavior during microdialysis. Neurosci Lett. 1990;118:169-71.

271. Andersen SL, Rutstein M, Benzo JM, Hostetter JC, Teicher MH. Sex differences in dopamine receptor overproduction and elimination. Neuroreport 1997;8:1495-8.

272. Hruska RE, Pitman KT. Distribution and Localization of Estrogen-Sensitive Dopamine Receptors in the Rat Brain. J Neurochem 1982;39:1418-23.

273. Bazzett TJ, Becker JB. Sex differences in the rapid and acute effects of estrogen on striatal D2 dopamine receptor binding. Brain Res. 1994;637:163-72.

274. Lewis-Hall FC, Wilson MG, Tepner RG, Koke SC. Fluoxetine vs. tricyclic antidepressants in women with major depressive disorder. J Women's Health. 1997;6:337-43.

275. Montejo-Gonzalez AL, Liorca G, Izquierdo JA, Ledesma A, Bousono M, Calcedo A, et al. SSRI-induced sexual dysfunction: fluoxetine, paroxetine, sertraline, and fluvoxamine in a prospective, multicenter, and descriptive clinical study of 344 patients. J Sex Marital Ther. 1997;23:176-94.

276. Hansen DG, Vach W, Rosholm JU, Søndergaard J, Gram LF, Kragstrup J. Early discontinuation of antidepressants in general practice: association with patient and prescriber characteristics. Fam Pract. 2004;21:623-9.

277. Krivoy A, Balicer RD, Feldman B, Hoshen M, Zalsman G, Weizman A, et al. The impact of age and gender on adherence to antidepressants: a 4-year population-based cohort study. Psychopharmacology. 2015;3385-90. https://doi.org/ 10.1007/s00213-015-3988-9. 